\title{
Ortaokul Öğretmenlerinin İş Doyumlarının Mesleki Tükenmişlik Düzeylerine Etkisi ${ }^{1}$
} \section{The Effect of Job Satisfaction of Secondary School Teachers on Their Occupational Burnout}

\author{
Mehmet Serhat DİR $\dot{I}^{2} \quad$ Erkan KIRAL $^{3}$
}

\author{
Başvuru Tarihi: 25.03.2016
}

Yayına Kabul Tarihi: 08.08.2016

DOI: $10.21764 /$ efd. 81587

\begin{abstract}
Özet: Araştırma; ortaokullarda görev yapan öğretmenlerin iş doyumlarının, mesleki tükenmişliklerine etkisini incelemek amacı ile gönüllü 162 öğretmenle yapılmıştır. Çalışma; nicel araştırma yöntemlerinden nedensel karşılaştırmalı ve ilişkisel tarama modelinde desenlenmiştir. Verilerin toplanmasında; Minnesota İş Doyum Ölçeği ve Maslach Tükenmişlik Ölçeği kullanılmıştır. Verilerin çözümlenmesinde betimsel ve kanıtlamasal istatiktik tekniklerinden yararlanılmıştır. Araştırma sonucunda; öğretmenlerin en yüksek duygusal tükenme düzeyine; iş doyumuna ilişkin ise en yüksek içsel iş doyum düzeyine sahip oldukları ortaya çıkmıştır. Kadın öğretmenlerin kişisel başarı boyutundaki tükenmişlik düzeylerinin erkek öğretmenlerden; 30 yaş ve altındaki öğretmenlerin; duyarsızlaşma boyutundaki tükenmişlik düzeylerinin, 31-35 yaş ile 36-40 yaş grubundaki öğretmenlerin tükenmişlik düzeylerinden; bekâr öğretmenlerin duyarsızlaşma boyutundaki tükenmişlik düzeylerinin evli öğretmenlerden; mesleğini istemeyerek seçen öğretmenlerin duygusal tükenme düzeylerinin, mesleğini isteyerek seçen öğretmenlerden anlamlı düzeyde yüksek olduğu tespit edilmiştir. Diğer taraftan; bulundukları okulun sosyo-ekonomik durumu düşük olan öğretmenlerin dışsal boyuttaki iş doyumu düzeylerinin, bulundukları okulun sosyo-ekonomik durumu orta olan öğretmenlerden; mesleğini istemeyerek seçen öğretmenlerin dışsal doyumlarının genel doyumlarından, genel doyumlarının da içsel doyumlarından anlamlı düzeyde düşük olduğu tespit edilmiştir. Öğretmenlerin tükenmişlik ve iş doyumu düzeyleri arasında negatif yönde anlamlı ilişkiler olduğu ve en yüksek ilişkinin ise öğretmenlerin duygusal tükenme düzeyleri ile genel doyum düzeyleri arasında olduğu görülmüsştür. Duygusal tükenmenin yordayıcılarının içsel ve dişsal doyum olduğu; duyarsızlaşmanın ve kişisel başarının ise tek yordayıcısının içsel doyum olduğu saptanmıştır. Öğretmenlerin tükenmişlerini azaltmak işdoyumlarını arttırmak için çeşitli önerilerde bulunulmuştur.
\end{abstract}

Anahtar Kelimeler: Mesleki tükenmişlik, iş doyumu, öğretmen, ortaokul.
Abstract: This study is conducted with 162 teachers to investigate the effect of job satisfaction of secondary school teachers on their occupational burnout levels. It is designed in casual comparative and correlational models from quantitative methods. For data collection Minnesota Job Satisfaction Scale and Maslach Burnout Inventory were used. In the analysis of data descriptive and probative statistical techniques were used. According to the results of the study, in term of burnout, teachers have emotional burnout and in terms of job satisfaction, they have intrinsic job satisfaction at the highest level. Results showed that, female teachers' burnout levels in the dimension of personal accomplishment is significantly higher than males, burnout levels of teachers who are at the age of 30 and below, is significantly higher than teachers' who are at the age of 31-35 and 36-40 in the dimension of depersonalization; single teachers' burnout levels in the dimension of depersonalization is significantly higher than married teachers'; burnout levels of teachers who had chosen their jobs involuntarily is significantly higher than teachers' who has chosen their jobs voluntarily in the dimension of emotional exhaustion. On the other hand, extrinsic job satisfaction levels of teachers who work in lower socio-economic areas, is significantly higher than teachers' working in medium level socio-economic areas; extrinsic job satisfaction levels of the teachers who had chosen their job involuntarily is significantly higher than their general job satisfaction and also their general job satisfaction level is significantly higher than their intrinsic satisfaction. It is also found that, there is significantly negative relationship between teachers' burnout and satisfaction levels and the highest relationship was seen between emotional exhaustion and general job satisfaction levels. It is determined that the predictors of emotional exhaustion are intrinsic and extrinsic satisfaction; the predictive of depersonalization and personal accomplishment is intrinsic satisfaction. Some suggestions to raise teachers' job satisfaction and to reduce their burnout levels are given.

Keywords: occupational burnout, job satisfaction, teacher, secondary school

\footnotetext{
${ }^{1}$ İkinci yazarın danışmanlığında yürütülen “Ortaokul Öğretmenlerinin İş Doyumlarının Mesleki Tükenmişlik Düzeylerine Etkisi” başlıklı yüksek lisans tezinden üretilen bu çalışma VIII. Uluslar Arası Eğitim Araştırmaları Kongresinde 6 Mayıs 2016 tarihinde sözlü bildiri olarak sunulmuştur.

2 Öğretmen, Dr. Reşit Galip Ortaokulu, serhatdiri@hotmail.com.

${ }^{3}$ Yrd. Doç. Dr., Adnan Menderes Üniversitesi Eğitim Fakültesi Eğitim Bilimleri Bölümü, erkankiral74@gmail.com.
} 


\section{Giriş}

Çalışma hayatı, insan yaşamının önemli parçalarından birini oluşturmaktadır. İnsanlar günlük yaşantılarının büyük bir kısmını iş yerlerinde ve iş ile ilgili çalışmalarını planlayarak geçirmektedirler. İnsanlar gerek iş yaşamında gerek günlük yaşamda çeşitli düzeylerde stres yaşamaktadırlar. Esasında yaşam içinde insanların stres yaşamaları doğal bir olgudur. Ancak bir kısım insanlar yüksek düzeyde stres yaşarlarken bir kısım insanlar ise düşük düzeyde stres yaşayabilmektedirler (Kıral, 2008). Önemli olan yükssek düzeyde stresi kötü sonuçlara yol açmadan yönetebilmektir (Rowshan, 2003). Özellikle toplumsal rollerin farklılaşması, kişilerarası ilişkilerde anlaşmazlıklar yaşanması, çalışma ortamlarında rekabetin ön plânda olması ve buna bağlı olarak da kişilerin kendilerini kanıtlama savaşı, çalışanlardan işlerini mükemmel şekilde yapmalarının istenmesi, kaynak sınırlığı gibi daha birçok neden çalışanların ruh sağlığını olumsuz olarak etkileyebilmekte ve onların stres yaşamalarına neden olabilmektedir (Norfolk, 1989). Öyle ki yönetilemeyen stres çalışanlarda gerek bireysel gerekse örgütsel anlamda ciddi problemlere yol açabilmektedir. Nitekim çalışanların sağlığını ve iş verimliliğini etkileyen pek çok sorunun temelinde de stres yatmaktadır (Cemaloğlu ve ErdemoğluŞahin, 2007). Günümüzde bireylerin her alanda maruz kaldığ zorlamalar, onların psikolojik dengelerini bozarak bir taraftan yaşamın devamı için gerekli olan enerjiyi açığa çıkarırken diğer taraftan tüm enerjilerini yok edebilecek bir çelişkiyle onları çaresiz, savunmasız ve zayıf bırakabilmektedir (Otacıŏglu, 2008). İnsanların; stres verici duygular (kızma, ağlama vb) karşısında nasıl davranacaklarını bilmemeleri onları içinden çıkılamaz zor durumlara sokabilmektedir.

Günümüzde bilişim, teknolojik ve sosyal alanlarda meydana gelen hızlı ve köklü değişimler, bireylerin günlük ve çalışma yaşamını etkileyerek onları istenmeyen pek çok durumla karşı karşıya bırakabilmektedir. İstenmeyen durumla karşı karşıya kalan insanlar kimi zaman stres verici durumlarla baş edebilmekte kimi zamansa stres verici durumlar karşısında yenilmişlik, çaresizlik, yalnızlık ve tükenmişlik gibi duygular yaşayabilmektedirler (Kıral, 2008). Nitekim insan yaşamı üzerinde fiziksel, zihinsel ve duygusal olarak bask1 oluşturan stres ve onun aşırı kronikleşmiş hâli olan tükenmişlik kavramı (Çapri, 2006) ilk olarak 1970'li yılların ortalarında, insanlarla ilişkileri fazla olan mesleklere özgü bir sendromu tanımlamak için kullanılmıştır (Barutçu ve Serinkan, 2008). O zamandan bu yana tükenmişlik ile ilgili araştırmacılar pekçok tanım yapmıştır. Maslach (1976) kişinin mesleğinin özgün anlamı ve amacından kopmasını, hizmet verdiği insanlarla ilgilenmemesini tükenmişlik olarak tanımlamıştır. Tükenmişlik; hem kişinin kendine hem de çalıştı̆̆ı örgüte aşırı şekilde zarar verebilmektedir. Tükenmişlik; iş doyumu, stres, yaşam doyumu ve yaşam kalitesi kavramlarıyla ilişkilidir. Bu kavramların birbiriyle ilişkili olduğu, kişilerin yaşam şartlarındaki değişik tepki ve tutumlarda görülebilmektedir. Stres faktörlerinin yoğun olduğu ve iş doyumu sağlanamayan örgütlerde çalışanların yaşam doyumu ve tükenmişlik düzeylerinin olumsuz yönde etkileneceği söylenebilir. Tükenmişlik, örgüt ve birey açısından ciddi sonuçlar doğuracağı için önlenmesi gereken bir durumdur (Avşaroğlu, Deniz ve Kahraman, 2005). Bu nedenle örgütlerde çalışanlarının iş doyumlarının artırılmasına yönelik yönetimsel uygulamalara gidilmeli ve alınması gereken önlemler alınmalıdır.

Dinamik bir olgu olan iş doyumu, bireysel ya da grupla ilişkili olabildiği gibi işin belirli bir kısmıla da ilişkili olabilir ve işin özellikleriyle çalışanın istekleri birbirine uyduğu zaman gerçekleşebilir (OkrayKocabıyık ve Çakıcı, 2008). İş doyumu bir kişinin, işini veya iş deneyimlerini değerlendirmesinden kaynaklanan zevkli ve olumlu duygular hissetmesi iken iş doyumsuzluğu bunun tam tersini yansıtmaktadır (Sempane, Rieger ve Roodt, 2002). Yöneticiler, çalışanların yalnızca ekonomik birer varlık olmadığını, aynı zamanda sosyal yönlerinin de bulunduğunu, ekonomik beklentilerinin haricinde, sosyal ve psikolojik ihtiyaçlarını karşılamak için bir örgütte çalıştıklarını göz önünde bulundurabilmelidirler. Çünkü çalışanlar örgütlerde sadece ekonomik ihtiyaçları karşılandığı için çalışmaya devam etmezler aynı zamanda sosyal ve psikolojik ihtiyaçlarınında örgüt tarafından karşılanmasını beklerler (Sağlam, 2007; Yı1maz ve Kıral, 2014). 
Psikolojik ve sosyal ihtiyaçlarının karşılanmasını onların iş doyumunu artırır. Bu nedenle çalışanların iş doyumlarının sağlanması aynı zamanda örgütlerin önemli sosyal ve psikolojik görevlerindendir (Akınc1, 2002). Toplumsal açık bir sistem olan okullarda öğretmenlerin iş doyumlarının yükseltilerek tükenmişliklerinin azaltılması oldukça önemlidir. Öğretmenin mesleğinde başarılı olabilmesi; fiziksel, sosyal ve ruhsal açıdan sağlıklı olmasına bağlı olan öğretmenin özellikleri (duygu, değer, davranış vb) ile iş yaşamının koşulları sürekli etkileşim halindedir. Bu etkileşimin sonucu olarak hem iş doyumu hem de tükenmişlik ortaya çıkabilmektedir (Özben ve Argun, 2003). Öğretmenlerin mesleklerini etkili bir şekilde yapabilmeleri, yeteneklerini algılayabilmeleri ve kendilerine olan özgüvenleri ile doğru orantılıdır. Ancak; öğretmenlerin karşılaştıkları ve mücadele etmek zorunda oldukları problemler, mesleklerinden doyum sağlayamamalarına ve mesleğin stresinden kaynaklanan tükenmişlik duygusunu yaşamalarına neden olabilmektedir (Karahan ve Uyanık-Balat, 2011). Nitekim çalışanların işlerinde çeşitli nedenlerle yaşadıkları iş doyumsuzluğu giderilmediğinde sonrasında buna bağlı olarak tükenmişliğin yaşanması olasıllğı ortaya çıkabilmektedir.

Öğretmenlerin iş doyumları ve mesleki tükenmişlikleri, sadece kendileri için değil, çalıştıkları eğitim kurumu açısından da çok önemlidir. Çünkü öğretmenlerin iş doyumları ve yaşadıkları mesleki tükenmişlik düzeyleri; ortaya konan hizmetin kalitesini ve okulun verimini, buna bağlı olarak da okulun amaçlarının gerçekleşmesini ve eğitim-öğretim ortamını etkileyebilmektedir. Yaptığı işten doyum sağlamadığını hisseden ve bunu da açıkça dile getiren öğretmenin tükenmesi neticesinde sunduğu eğitimin kalitesi de azaltabilmektedir. $\mathrm{Bu}$ nedenle; öğretmenlerin işlerinden sağladıkları doyumun ve yaşadıkları mesleki tükenmişlik düzeyinin bilinmesi ve birbirleri ile olan ilişkisinin ortaya çıkarılması, bu konuda öğretmenlerde bir farkındalık yaratılarak onların tükenmişliklerinin azaltılması ve iş doyumlarının artmasına yönelik öneriler sunulmuştur. Ortaya konan önerilerin karar alıcılar tarafından uygulamaya konulmasının eğitim öğretimin kalitesininin artmasına katkı sağlayacağı umulmaktadır. Nitekim bu çalışmanın amacı da ortaokul öğretmenlerinin iş doyumlarının, mesleki tükenmişlik düzeylerine etkisini ortaya çıkarmaktır. Bu amacı ortaya çıkarmak için aşağıdaki sorulara yanıt aranmıştır.

(1) Öğretmenlerin mesleki tükenmişlik ve iş doyum düzeyleri nedir?

(2) Öğretmenlerin mesleki tükenmişlik ve iş doyum düzeyleri demografik değiş̧kenlere göre değişmekte midir?

(3) Öğretmenlerin iş doyumu ile tükenmişlik düzeyleri arasında anlamlı bir ilişki var mıdır?

(4) Öğretmenlerin iş doyum düzeyleri tükenmişliklerini yordamakta mıdır?

\section{Yöntem}

Ortaokul öğretmenlerinin iş doyumu ve mesleki tükenmişlik düzeylerinin ve iş doyumlarının tükenmişliklerine etkisinin belirlenmesini amaçlayan bu araştırmanın modeli, nedensel karşılaştırmalı ve ilişkisel tarama modelidir (Balc1, 2009; Karasar, 2012). Bu araştırma ile öğretmenlerin iş doyumu ve tükenmişlik düzeyleri; öğretmenlerin iş doyumlarının, tükenmişliklerine etkisi öğretmenlere uygulanan ölçeklerle ortaya çıkarılmaya çalışılmıştır.

\section{Çalışma Grubu}

$\mathrm{Bu}$ araştırmanın çalışma grubunu, Aydın ili İncirliova ilçesinde bulunan 7 kamu ortaokulunda görevli olan öğretmenlerden araştırmaya gönüllü olarak katılan 162 öğretmen oluşturmaktadır. Araştırmaya katılan öğretmenlerin demografik özelliklerine ilişkin elde edilen verilerin analizi sonucunda; öğretmenlerin; \% 49.4'ünün (n: 80) erkek, \% 50.6'sının (n: 82) kadın; \% 33.3'ünün (n: 54) 30 yaş ve altı, \% 27.1'inin (n: 44) 
31-35 yaş, \% 21'inin (n: 34) 36-40 yaş, \% 18.6'sının (n: 30) 41 ve üzeri; \% 50'sinin (n: 81) sözel, \% 28.4'ünün (n: 46) sayısal, \% 21.6'sının (n: 35) yetenek dersleri branşında; \% 21.6'sının (n: 35) 5 yıl ve altı, \% 30.9'unun (n: 50) 6-10 y11, \% 24.1'inin (n: 39) 11-15 y11, \% 23.4'ünün (n: 38) 16 y1l ve üzeri kıdeme; \% 4.3'ünün (n: 7) önlisans, \% 90.8'inin (n:147) lisans, \% 4.9'unun (n: 8) lisansüstü mezunu; \%18.5'inin (n: 30) bekar, \% 81.5'inin (n:132) evli; \% 40,1'inin (n: 65) çocuğu yok, \% 29.6'sının (n: 48) bir, \% 24.1 (n: 39) iki, $\%$ 6.2'sinin (n: 10) üç çocuğu; \% 29'unun (n:47) görev yaptıkları okulda bir yıl ve altında, \% 34'ünün (n: 55) 2 yı1, \% 37'sinin (n: 60) 3 yıl ve üzeri hizmeti; \% 56.2'sinin (n: 91) görev yaptıkları okulun sosyo-ekonomik durumunun düşük, \% 43.8'inin (n: 71) orta; \% 86.4'ünün (n: 140) mesleğini kendi isteği ile seçmiş ve \%13.6'sının (n: 22) seçmemiş olduğu tespit edilmiştir.

Veri Toplama Aracı

Araştırma verilerini toplamak için Minnesota İş Doyumu Ölçeği ve Maslach Tükenmişlik Envanteri kullanılmıştır. Kullanılan ölçeklerin özellikleri aşağıda açıklanmıştır.

Minnesota Işs Doyum Ölçeği (MIDÖ): Öğretmenlerin iş doyumu düzeylerini belirlemek amaciyla; Weiss, Dawis, England ve Lofquist (1967) tarafından ortaya konulmuştur. Ölçek; 5'li Likert tipinde [Hiç Memnun değilim (1) - Çok Memnunum (5)] bir ölçek olup, iki boyuttan [İçsel Doyum (ID) ve Dışsal Doyum (DD)] ve toplam 20 maddeden oluşmaktadır. Ölçek; Baycan (1985) tarafından Türkçe’ye uyarlanarak geçerlik ve güvenirlik çalışması yapılmış ve pek çok araştırmacı tarafından da (Uyar ve Erdinç, 2011; Yelboğa; 2007 vb.) kullanılmıştır. Baycan (1985) tarafından yapılan çalışmada ölçeğin geneli için Cronbach Alpha değeri = .77 olarak bulunmuştur İçsel doyum; ahlaki değerler, başkalarına yardım, otorite, yeteneklerini kullanma, sorumluluk, yaratıcılık, takdir edilme, başarı ve toplumda saygınlık ifadelerini içeren 12 maddeden oluşmaktadır. Dışsal doyum; terfi imkânı, kurum politikası ve uygulamaları, çalışma arkadaşları, çalışma koşulları, ücret, yöneticinin yönetim anlayışı, yöneticinin teknik desteği ve iş garantisi ifadelerini içeren 8 maddeden oluşmaktadır (Karataş ve Güleş, 2010). Bu araştırma için yapılan çalışmada Cronbach Alfa katsayılarının genel, içsel ve dışsal doyum için. 79 ile .87 arasında değiştiği tespit edilmiştir.

Maslach Tükenmişlik Ölçeği (MTÖ): Öğretmenlerin tükenmişliğini değerlendirmek üzere, Maslach ve Jackson (1981) tarafından geliştirmiş ve Ergin (1992) tarafından Türkçeye uyarlanarak geçerlik ve güvenirlik çalışması yapılmıştır. Çalışmada Türkçe uyarlaması yapılan 5 Likert [Hiçbir Zaman (0)- Her Zaman (4)] tipi formu kullanılmıştır. MTÖ, 22 madde ve üç alt ölçekten oluşan bir ölçme aracıdır. Bu alt ölçekler; duygusal tükenme, duyarsızlaşma ve kişisel başarıdır. Duygusal tükenme; duygusal enerjinin boşalması olarak gelişen yorgunluk, bitkinlik ve aşırı yüklenilmiş olma durumları tanımlamakta ve 9 maddeden oluşmaktadır. Duyarsızlaşma; kişinin iş ortamında hizmet verdiği kişilere karşı duygudan yoksun bir şekilde davranması olarak tanımlanmakta ve 5 maddeden oluşmaktadır. Kişisel başarı; işyerinde bireyin başarı duygusunda meydana gelen azalma olarak tanımlanmakta ve 8 maddeden oluşmaktadır (Gündüz, 2005). Ölçek pekçok araştırmacı (Ören ve Türkoğlu, 2006; Cemaloğlu ve Kayabaşı, 2007; Karakelle ve Canpolat, 2008; Üngüren, Doğan, Özmen ve Tekin, 2010; Budak ve Sürgevil, 2005; Erkul ve Dalgıç, 2014 vb) tarafından kullanılmıştır. Ergin (1992) tarafından yapılan güvenirlik çalışmasında üç alt boyutta Cronbach Alpha değerlerinin .65 ile .83 arasında olduğu tespit edilmiştir. Bu araştırma için yapılan çalışma da ise Cronbach Alfa katsayılarının .73 ile .85 arasında olduğu bulunmuştur. Duygusal Tükenme ve Duyarsızlaşma alt boyutları olumlu, Kişisel Başarı alt boyutu ise olumsuz ifadeler içermektedir ve bu olumsuz ifadelerin ters yönde puanlanmaları gerekmektedir. Tükenmişliğin bu üç alt boyutu arasındaki ilişkiye bakıldığında, her alt ölçeğin puanı ayrı ayrı değerlendirilir ve tek bir toplam puanla birleştirilemez (Maslach ve Jackson, 1985; Çam, 1992). 


\section{Veri Analizi}

Verilerin çözümlenmesinde frekans, yüzde, ortalama, parametrik ve parametrik olmayan fark testleri, korelasyon ve çoklu regresyon analizi testleri kullanılmıştır. Araştırmada verilerin istatistiksel analizi, bağımsız değişkenlerin (içsel dışsal ve genel) bağımlı değişken (tükenmişlik düzeyleri) üzerindeki etkisini ortaya koyacak bir model içinde ele alınmıştır. Öğretmenlerin iş doyumu ve tükenmişlik düzeyleri, ortalama ve standart sapma ile; öğretmenlerin tükenmişlik düzeylerinin bağımsız değişkenlere (iş doyumu, cinsiyet, yaş, branş, mesleki kıdem vb gibi) göre anlamlı farklılaşma gösterip göstermediği normallik koşullarını sağlayan durumlarda parametrik fark testleri (t-testi ve ANOVA) ve normallik koşullarını sağlamayan durumlarda $(\mathrm{n}<30)$ ise non-parametrik fark testleri (Kruskal Wallis testi ve Mann-Whitney U) ile analiz edilmiştir. ANOVA testinde ortaya çıkan farkın hangi gruplardan kaynaklandığını anlamak amacıyla gruptaki örneklem sayısı göz önünde tutularak Scheffe testi, Kruskal Wallis testinde orta çıkan farklılığın kaynağını bulmak içinse Mann Whitney U Testi yapılmıştır (Ural ve Kılıç, 2005).

Verilerin normallik koşullarını sağlayıp sağlamadığına ilişkin merkeze eğilim ölçülerine (ortlalama, ortanca ve tepe değer) bakılmış bunların birbirine yakın olduğu, ayrıca yine normalliği test edilecek veri grubunun basıklık ve çarpıklı katsayına bakılmış bu değerlerin de +1 ile -1 arasında olduğu yine Kolmogorov Smirnow testi sonucu normalliğin sağlandığı ( $>$ >05) görülmüştür. Ancak bazı bağımsız değişkenlerinin (eğitim durumu, çocuk sayısı, mesleği kendi isteği ile seçme) sayısının 30'un altında olduğu ve normallik koşullarını sağlamadığı görülmüştür. Bu nedenle bu veri grupları ile işlem yapılırken nonparametric testler (Kruskal Wallis testi ve Mann-Whitney U) kullanılmıştır (Can, 2016). Öğretmenlerin iş doyumu düzeyleri ile tükenmişlik düzeyleri arasında anlamlı ilişki olup olmadığı normallik koşullarını sağladığı için Pearson Momentler Çarpımı Korelasyon Katsayısı ile sınanmıştır (Tavşancıl, 2006). Hem iş doyumu hemde tükenmişlik ölçeği eşit aralıklı ölçekler olup, normal dağılım sergiledikleri; yordayıcı değişkenler ile yordanan değişkenler arasında doğrusal bir ilişkinin olması ve yordanan değişkenlerin birbirinden bağımsız olması gibi nedenlerden dolayı iş doyumunun tükenmişlik üzerindeki etkisi çoklu regresyon analizi ile incelenmiştir. Değerlendirme aşamasında korelasyon katsayısının, 0.00-0.29 arasında olması ise düşük; 0.30- 0.69 arasında olması orta ve 0.70-1.00 arasında olması ise yüksek olarak yorumlanmıştır (Büyüköztürk, 2016). Elde edilen istatistiklerin anlamlılığı .05 düzeyinde çift yönlü olarak sınanmıştır.

\section{Bulgular}

Araştırma sonucu elde edilen bulgular araştırmanın amacına uygun olarak; öğretmenlerin mesleki tükenmişlik düzeyine ilişkin bulgular, öğretmenlerin iş doyumu düzeyine ilişkin bulgular ve öğretmenlerin mesleki tükenmişlik ile iş doyumu düzeyleri arasındaki ilişkiye ilişkin bulgular şeklinde aşağıda verilmiştir.

Öğretmenlerin Mesleki Tükenmişlik Düzeylerine İlişkin Bulgular

Öğretmenlerin mesleki tükenmişlik düzeylerine ilişkin elde edilen bulgular Tablo 1'de verilmiştir.

Tablo 1. Ortaokul Öğretmenlerin Mesleki Tükenmişlik Düzeyleri

\begin{tabular}{llcc}
\hline Değişken & Boyutlar & $\overline{\mathbf{X}}$ & $\mathbf{S}$ \\
\hline \multirow{3}{*}{ Mesleki Tükenmişlik } & Duygusal Tükenme & 14.35 & 6.28 \\
& Kişisel Başarı & 9.74 & 4.60 \\
& Duyarsızlaşma & 4.76 & 3.39 \\
\hline
\end{tabular}


Tablo1'den izlenebileceği gibi ortaokul öğretmenlerinin en çok duygusal tükenme boyutunda sonra ise sırasıyla kişisel başarı ve duyarsızlaşma boyutlarında tükenmişlik yaşadıkları söylenebilir. Öğretmenlerin duygusal tükenme boyutu "orta" düzeyde iken; duyarsızlaşma ve kişisel başarı boyutları "düşük" düzeydedir.

Cinsiyet değişkenine göre öğretmenlerin tükenmişlik düzeyleri; duygusal tükenme ve duyarsılaşma boyutlarında anlamlı bir farklılık göstermezken; kişisel başarı boyutunda anlamlı bir farklılık göstermektedir $\left[\mathrm{t}_{(160)}=2.115, \mathrm{p}<.05\right]$. Bu sonuca göre, kadın öğretmenlerin kişisel başarı boyutundaki tükenmişlik düzeyleri $(\overline{\mathrm{X}}=10.49 ; \mathrm{S}=4.16)$, erkek öğretmenlerden $(\overline{\mathrm{X}}=8.98 ; \mathrm{S}=4.92)$ daha yüksektir.

Yaş değişkenine göre öğretmenlerin tükenmişlik düzeyleri; duygusal tükenme ve kişisel başarı boyutlarında anlamlı bir farklılık göstermezken; duyarsızlaşma $\left[\mathrm{F}_{(3-158)}=3.986 ; \mathrm{p}<.05\right]$ boyutunda anlamlı bir farkl11ık göstermektedir. Bu farkın hangi yaş grupları arasında olduğunu bulmak amacıyla çoklu karşılaştırma testi yapılmış; 30 yaş ve altındaki öğretmenlerin duyarsızlaşma boyutundaki tükenmişlik düzeylerinin $(\overline{\mathrm{X}}=5.54$; $\mathrm{S}=3.65) ; 31-35$ yaş grubundaki öğretmenlerin $(\overline{\mathrm{X}}=5.19 ; \mathrm{S}=3.47)$ ve $36-40$ yaş grubundaki öğretmenlerin $(\overline{\mathrm{X}}$ $=3.15 ; \mathrm{S}=2.41)$ tükenmişlik düzeylerinden anlamlı şekilde daha yüksek olduğu bulunmuştur.

Medeni durum değişkenine göre öğretmenlerin tükenmişlik düzeyleri; duygusal tükenme ve kişisel başarı boyutlarında anlamlı bir farklılık göstermezken; duyarsızlaşma $\left[\mathrm{t}_{(160)}=2.188 ; \mathrm{p}<, 05\right]$ boyutunda anlamlı bir fark göstermektedir. Bekâr öğretmenlerin duyarsızlaşma boyutundaki tükenmişlik düzeylerinin $(\overline{\mathrm{X}}=5.97$; $\mathrm{S}=$ 4.21), evli öğretmenlerden ( $\overline{\mathrm{X}}=4.48 ; \mathrm{S}=3.13)$ daha yüksek olduğu bulunmuştur.

Mesleğini kendi isteği ile seçip seçmeme değişkenine göre öğretmenlerin tükenmişlik düzeylerinde; duyarsızlaşma ve kişisel başarı boyutlarında anlamlı bir fark ortaya çıkmazken; duygusal tükenme [U=947; $\mathrm{p}<$.05] boyutunda anlamlı farklılık ortaya çıkmıştır. Mesleğini istemeyerek seçen öğretmenlerin duygusal tükenme sıra sayıları ortalamalarının $(\overline{\mathrm{R}}=108.48)$, mesleğini isteyerek seçen öğretmenlerin sıra sayıları ortalamalarından $(\overline{\mathrm{R}}=77.26)$ daha yüksek düzeyde olduğu bulunmuştur.

Öğretmenlerin branşına, kıdemine, eğitim durumuna, çocuk sayısına, çalışılan okuldaki hizmet yılına ve görev yaptıkları okulun sosyo ekonomik durumuna göre tükenmişlik düzeylerinde; duygusal tükenme, duyarsızlaşma ve kişisel başarı boyutlarnda anlamlı bir farklılık bulunmamıştır.

Öğretmenlerin Iş Doyumu Düzeylerine Ilişkin Bulgular

Öğretmenlerin iş doyumu düzeylerine ilişkin elde edilen bulgular Tablo 2'de verilmiştir.

Tablo 2. Ortaokul Öğretmenlerin İş Doyumu Düzeyleri

\begin{tabular}{llll}
\hline Değişken & Boyutlar & $\overline{\mathbf{X}}$ & $\mathbf{S}$ \\
\hline \multirow{2}{*}{ İş doyumu } & İçsel Doyum & 3.83 & .58 \\
& Genel Doyum & 3.56 & .59 \\
& Dişsal Doyum & 3.17 & .77 \\
\hline
\end{tabular}

Tablo 2'de görüldüğü gibi ortaokul öğretmenlerinin görece en çok içsel doyum sağladığı, bunu sırasıyla genel ve dişsal doyumun takip ettiği bulunmuştur. Öğretmenlerin içsel, dişsal ve genel iş doyumu düzeyleri "memnunum" düzeyindedir.

Öğretmenlerin iş doyumu düzeyleri görev yaptıkları okulun sosyo-ekonomik durumu değişkenine göre; içsel ve genel iş doyumu boyutlarında anlamlı bir farkl11ı göstermezken; dışsal $\left[\mathrm{t}_{(160)}=4.216 ; \mathrm{p}<.05\right]$ iş doyumu 
boyutunda anlamlı bir fark göstermektedir. Görev yaptıkları okulun sosyo-ekonomik durumu düşük olan öğretmenlerin dişsal boyuttaki iş doyumu düzeyleri $(\overline{\mathrm{X}}=3.07 ; \mathrm{S}=.81)$, görev yaptıkları okulun sosyoekonomik durumu orta olan öğretmenlerden $(\overline{\mathrm{X}}=3.29 ; \mathrm{S}=.72)$ daha düşüktür.

Öğretmenlerin iş doyumu düzeyleri mesleklerini kendi istekleri ile seçip-seçmeme değişkenine göre; içsel $[\mathrm{U}=1126 ; \mathrm{p}<.05]$, dişsal $[\mathrm{U}=901 ; \mathrm{p}<.05]$ ve genel $[\mathrm{U}=924 ; \mathrm{p}<.05]$ iş doyumu boyutlarında anlamlı bir farkl11ık göstermektedir. Mesleğini isteyerek seçen öğretmenlerin sıra sayıları ortalamaları; içsel $(\overline{\mathrm{R}}=84.46)$, dişsal $(\overline{\mathrm{R}}=86.06)$ ve genel $(\overline{\mathrm{R}}=85.90)$ doyum düzeylerinde mesleğini istemeyerek seçen öğretmenlerin içsel $(\overline{\mathrm{R}}=62.68)$, dışsal $(\overline{\mathrm{R}}=52.45)$ ve genel $(\overline{\mathrm{R}}=53.52)$ doyum düzeylerindeki sıra sayı ortalamalarından anlamlı düzeyde yüksek bulunmuştur.

Öğretmenlerin cinsiyetine, yaşına, branşına, kıdemine, eğitim durumuna, çocuk sayısına, medeni durumuna, çalıştıkları okuldaki hizmet yılına göre iş doyum düzeylerinde; boyutlar bazında ve genel olarak anlamlı bir farklılık bulunmamıştır.

Öğretmenlerin Mesleki Tükenmişlikleri İle İş Doyumu Düzeyleri Arasındaki İlişkiye İlişkin Bulgular

Ortaokul öğretmenlerinin mesleki tükenmişlik ve iş doyumu düzeyleri arasındaki ilişkiye yönelik Korelasyon testi sonuçları Tablo 3'de verilmiştir.

Tablo 3. Öğretmenlerin Işs Doyumu ve Tükenmişlik Düzeyleri Arasındaki İlişki İçin Pearson Momentler Çarpım Korelasyon Katsayısı Sonuçları

\begin{tabular}{lllllll}
\hline & ID & DD & GD & DT & D & KB \\
\hline İD & - & & & & & \\
DD &, $611^{* *}$ & - & & & & \\
GD &, $909^{* *}$ &, $885^{* *}$ & - & & & \\
DT &,$- 422^{* *}$ &,$- 435^{* *}$ &,$- 477^{* *}$ & - & & \\
D &,$- 318^{* *}$ &,$- 255^{* *}$ &,$- 321^{* *}$ &, $576^{* *}$ & - & \\
KB &,$- 451^{* *}$ &,$- 176^{*}$ &,$- 358^{* *}$ &, $411^{* *}$ &, $363^{* *}$ & - \\
\hline
\end{tabular}

İD: İçsel Doyum; DD: Dışsal Doyum; GD: Genel Doyum; DT: Duygusal Tükenme; D:

Duyarsızlaşma; KB: Kişisel Başarı; p değeri $.05^{*}$ ve $.01^{* *}$ düzeyinde anlamlıdır.

Tablo 3'de görüldüğü gibi öğretmenlerin içsel doyumlarının; dışsal doyumla orta düzeyde pozitif yönde ( $\mathrm{r}=$ $.61 ; \mathrm{p}<.01)$; genel doyumla yüksek düzeyde pozitif yönde $(\mathrm{r}=.91 ; \mathrm{p}<.01)$; duygusal tükenmeyle $(\mathrm{r}=-.42$; $\mathrm{p}<.01)$; duyarsızlaşmayla $(\mathrm{r}=-.32 ; \mathrm{p}<.01)$ ve kişisel başarıyla $(\mathrm{r}=-.45 ; \mathrm{p}<.01)$ orta düzeyde negatif yönde anlamlı ilişkilerinin olduğu anlaşılmaktadır. Öğretmenlerin dışsal doyumlarının; genel doyumla yüksek düzeyde pozitif yönde $(\mathrm{r}=.89 ; \mathrm{p}<.01)$; duygusal tükenmeyle orta düzeyde negatif yönde $(\mathrm{r}=-.44 ; \mathrm{p}<.01)$; duyarsızlaşmayla $(r=-.26 ; p<.01)$ ve kişisel başarıyla $(r=-.18 ; p<.01)$ düşük düzeyde negatif yönde anlamlı ilişkilerinin olduğu tespit edilmiştir. Öğretmenlerin genel doyumlarının; duygusal tükenmeyle $(r=-.48 ; \mathrm{p}<$ $.01)$; duyarsızlaşmayla $(\mathrm{r}=-.32 ; \mathrm{p}<.01)$ ve kişisel başarıyla $(\mathrm{r}=-.36 ; \mathrm{p}<.01)$ orta düzeyde negatif yönde anlamlı ilişkilerinin olduğu tespit edilmiştir. Öğretmenlerin duygusal tükenmelerinin; duyarsızlaşmayla ( $\mathrm{r}=$ $.58 ; \mathrm{p}<.01)$ ve kişisel başarıyla $(\mathrm{r}=.41 ; \mathrm{p}<.01)$ orta düzeyde pozitif yönde anlamlı ilişkilerin olduğu anlaşılmaktadır. Öğretmenlerin duyarsızlaşmalarının; kişisel başarıyla olan ilişkisi incelendiğinde ise ikisi arasında orta düzeyde pozitif yönde anlamlı bir ilişki olduğu görülmektedir $(r=.36 ; \mathrm{p}<.01)$.

Duygusal Tükenmeyi; iş doyumunun alt boyutlarının yordayıp yordamadığını belirlemek amacıyla yapılan çoklu regresyon analizi sonuçları Tablo 4'de verilmiştir. 
Tablo 4. Duygusal Tükenmenin Yordanmasına İlişkin Çoklu Regresyon Analizi Sonuçları

\begin{tabular}{llllll}
\hline Boyut/Değişken & B & S & B & t & p \\
\hline Sabit & 31.983 & 2.933 & - & 10.904 & .000 \\
İçsel Doyum & -2.706 & .957 & -.249 & 2.827 & .005 \\
D1şsal Doyum & -2.294 & .714 & -.283 & 3.212 & .002 \\
\hline $\mathrm{R}=.477 ; \mathrm{R}^{2}=.228 ; \mathrm{F}_{(2-159)}=23.478 ; \mathrm{p}=.000$ & & & & \\
\hline
\end{tabular}

Tablo 4 incelendiğinde; içsel ve dışsal doyum boyutlarının doğrusal kombinasyonunun öğretmenlerin duygusal tükenmişliğini anlamlı bir biçimde yordadığ $\left(\mathrm{R}=.477 ; \mathrm{R}^{2}=.228\right)$ görülmektedir $\left[\mathrm{F}_{(2-159)}=23.478\right.$; $\mathrm{p}<0.01]$. Söz konusu bağımsız değişkenler, duygusal tükenmeye ait varyansın \% 23'ünü açıklamaktadır. Regresyon katsayısının anlamlılı̆̆ına ilişkin $\mathrm{t}$ testi sonuçları incelendiğinde, hem içsel doyumun $(\beta=-.249$; $\left.\mathrm{t}_{(161)}=2.83 ; \mathrm{p}<.05\right)$ hem de dişsal doyumun $\left(\beta=-.283 ; \mathrm{t}_{(161)}=3.21 ; \mathrm{p}<.05\right)$ duygusal tükenmenin anlamlı birer yordayıcısı olduğu görülmektedir. Standartlaştırılmış regresyon katsayılarına göre, yordayıcı değişkenlerin duygusal tükenmişlik üzerindeki göreli önem sırası; içsel doyum ve dışsal doyum şeklindedir. Regresyon analizi sonuçlarına göre duygusal tükenmişliğin yordanmasına ilişkin regresyon eşitliği aşağıda verilmiştir.

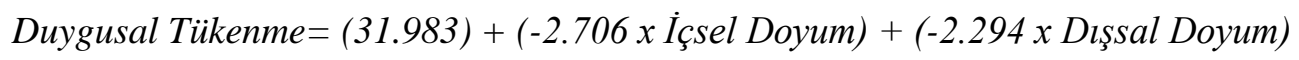

Duyarsızlaşmayı; iş doyumu boyutlarının yordayıp yordamadığını belirlemek amacıyla yapılan çoklu regresyon analizi sonuçları Tablo 5'te verilmiştir.

Tablo 5. Duyarsızlaşmanın Yordanmasına İlişkin Çoklu Regresyon Analizi Sonuçları

\begin{tabular}{lrrrrr}
\hline Boyut/Değişken & $\mathbf{B}$ & $\mathbf{S}$ & $\boldsymbol{\beta}$ & $\mathbf{t}$ & $\mathbf{p}$ \\
\hline Sabit & 11.921 & 1.701 & - & 7.006 & .000 \\
İçsel Doyum & -1.522 & .555 & -.260 & -2.742 & .007 \\
Dişsal Doyum & -.420 & .414 & -.096 & -1.014 & .312 \\
\hline $\mathrm{R}=.327 ; \mathrm{R}^{2}=.107 ; \mathrm{F}_{(2-159)}=9.540 ; \mathrm{p}=.000$ & & & & \\
\hline
\end{tabular}

Tablo 5 incelendiğinde; içsel ve dışsal doyum boyutlarının doğrusal kombinasyonunun öğretmenlerin duyarsızlığını anlamlı bir biçimde yordadığı $\left(R=.327 ; R^{2}=.107\right)$ görülmektedir $\left[F_{(2-159)=} 9.540 ; p<0.01\right]$. Söz konusu bağımsız değişkenler, duyarsızlaşmaya ait varyansın yaklaşık \%11'ini açıklamaktadır. Regresyon katsayısının anlamlılığına ilişkin $t$ testi sonuçları incelendiğinde içsel doyumun $\left(\beta=-.260 ; \mathrm{t}_{(161)}=2.74 ; \mathrm{p}<\right.$ $.05)$ duyarsızlaşmanın anlamlı bir yordayıcısı olduğu görülürken; dışsal doyumun $\left(\beta=-.096 ; \mathrm{t}_{(161)}=1.01 ; \mathrm{p}>\right.$ .05) duyarsızlaşmanın anlamlı bir yordayıcısı olmadığ görülmektedir. Standartlaştırılmış regresyon katsayılarına göre, yordayıcı değişkenlerin duyarsızlaşma üzerindeki göreli önem sırası; içsel doyum ve dışsal doyum şeklindedir. Regresyon analizi sonuçlarına göre duyarsızlığın yordanmasına ilişkin regresyon eşitliği aşă̆ıda verilmiştir.

Duyarsızlaşma $=(11.921)+(-1.522 \times$ Íçsel Doyum $)+(-.420 \times$ Dışsal Doyum $)$

Kişisel Başarıyı; iş doyumu alt ölçeklerinin yordayıp yordamadığını belirlemek amacıyla yapılan çoklu regresyon analizi sonuçları Tablo 6'da verilmiştir. 
Tablo 6. Kişisel Başarının Yordanmasına İlişkin Çoklu Regresyon Analizi Sonuçları

\begin{tabular}{lrrrrr}
\hline Boyut/Değişken & \multicolumn{1}{c}{ B } & \multicolumn{1}{c}{ S } & \multicolumn{1}{c}{$\boldsymbol{\beta}$} & t & p \\
\hline Sabit & 23.467 & 2.160 & - & 10.863 & .000 \\
İçsel Doyum & -4.366 & .705 & -.548 & -6.194 & .000 \\
Dişsal Doyum & .945 & .526 & .159 & 1.795 & .074 \\
\hline $\mathrm{R}=.468 ; \mathrm{R}^{2}=.219 ; \mathrm{F}_{(2-159)}=22.348 ; \mathrm{p}=.000$ & & & & \\
\hline
\end{tabular}

Tablo 6 incelendiğinde; içsel ve dışsal doyum boyutlarının doğrusal kombinasyonunun öğretmenlerin kişisel başarılarını anlamlı bir biçimde yordadığ $\left(R=.468 ; R^{2}=.219\right)$ görülmektedir $\left[\mathrm{F}_{(2-159)=} 22.348 ; \mathrm{p}<.01\right]$. Söz konusu bağımsız değişkenler, kişisel başarıya ait varyansın \% 22'sini açıklamaktadır. Regresyon katsayısının anlamlılığına ilişkin $\mathrm{t}$ testi sonuçları incelendiğinde içsel doyumun $\left(\beta=-.548, \mathrm{t}_{(161)}=6.19 ; \mathrm{p}<.05\right)$ kişisel başarının anlamlı bir yordayıcısı olduğu görülürken; dışsal doyumun $\left(\beta=.159, \mathrm{t}_{(161)}=1.80 ; \mathrm{p}>.05\right)$ kişisel başarının anlamlı bir yordayıcısı olmadığı görülmektedir. Standartlaştırılmış regresyon katsayılarına göre, yordayıcı değişkenlerin kişisel başarı üzerindeki göreli önem sırası; içsel doyum ve dışsal doyum şeklindedir. Regresyon analizi sonuçlarına göre kişisel başarının yordanmasına ilişkin regresyon eşitliği aşağıda verilmiştir.

Kişisel Başarı $=(23.467)+(-4.366$ x İçsel Doyum $)+(.945 x$ Dlşsal Doyum $)$

\section{Sonuç, Tartışma ve Öneriler}

Araştırmanın sonuçlarına göre öğretmenler en yüksek düzeyde duygusal tükenme, ikinci sırada kişisel başarı ve en düşük düzeyde ise duyarsızlaşma boyutlarında tükenmektedirler. Öğretmenlerin duygusal tükenme boyutu "orta" düzeyde iken; duyarsızlaşma ve kişisel başarı boyutları "düşük" düzeydedir. Öğretmenlerden beklentilerin çok yüksek olması, buna karşın imkânların ve kaynakların az olması öğretmenlerin görece yüksek düzeyde duygusal tükenmişlik yaşamalarına neden olabilir. Bununla birlikte, öğretmenlerin görece kişisel başarı ve duyarsızlaşma boyutunda düşük düzeyde tükenmişlik yaşaması onların mesleklerinde kendilerini yeterli görmeleri ve insanlara karşı olumlu duygular hissetmeleri şeklinde yorumlanabilir. Teltik'in (2009) araştırmasında da öğretmenler; duygusal tükenme ve duyarsızlaşma boyutlarında orta düzeyde, kişisel başarı boyutunda ise düşük düzeyde tükenmişlik yaşamaktadırlar. Yıldız'ın (2012) rehber öğretmenler ile gerçekleştirdiği çalışmasında, öğretmenlerin duygusal tükenme ve duyarsızlaşma düzeyleri düşük iken kişisel başarısızlık düzeyleri yüksek çıkmıştır. Çavuşoğlu (2005) ve Yılmaz-Toplu'nun (2012) çalışmalarında ise öğretmenlerde duygusal tükenme, duyarsızlaşma ve kişisel başarı boyutlarında düşük düzeyde tükenmişlik görüldüğü saptanmıştır.

Öğretmenlerin cinsiyetinin; duygusal tükenme ve duyarsızlaşma boyutlarında anlamlı bir farklılık göstermediği; ancak kişisel başarı boyutunda kadın öğretmenlerin tükenmişlik düzeylerinin erkek öğretmenlerden anlamlı düzeyde yüksek olduğu bulunmuştur. Kayabaşı (2008) ve Karahan ve UyanıkBalat'ın (2011) çalışmalarında da araştırmayla benzer şekilde öğretmenlerin cinsiyetleri ile sadece kişisel başarı düzeyleri arasında anlamlı fark bulunmuştur. İki araştırmada da erkek öğretmenlerin kişisel başarı alt boyutu puanları kadın öğretmenlerin puanlarından yüksektir. Söz konusu çalışmalarda erkek öğretmenlerin daha yüksek kişisel başarısızlık yaşamalarına rağmen bu araştırmada kadın öğretmenlerin daha yüksek düzeyde kişisel başarısızlık göstermesinin nedeni; söz konusu çalışmaların ilkokul ve özel eğitim okul türleri üzerinde yapılmış olması olabilir. Dolunay (2002), Özben ve Argun (2003), Avşaroğlu, Deniz ve Kahraman (2005), Başören (2005), Çavuşoğlu (2005), Çağlıyan (2007), Çavuş, Gök ve Kurtay (2007), Oruç (2007), 
Yoğun-Erçen (2007), Cemaloğlu ve Erdemoğlu-Şahin (2007), Özcan (2008), Başol ve Altay (2009), Dilber (2009), Polat, Topuzoğlu, Gürbüz, Hotalak, Kavak, vd. (2009), Çağlar ve Demirtaş (2011), Çelikkaleli (2011), Darmody ve Smyth (2011), Yılmaz-Toplu (2012), Adiloğulları (2013), Aydemir (2013), Çelebi (2013), Demirdöğen (2013), Goswami (2013), Gündoğdu (2013), Yalçın (2013), Yılmaz (2013), Bilgen ve Genç (2014) öğretmenlerin; Izgar (2000) ise okul yöneticilerinin tükenmişlik düzeylerinin cinsiyetlerine göre farklılaşmadığı sonucuna ulaşmışlardır. Bu çalışmada kişisel başarı boyutunda kadınların erkeklerden daha yüksek tükenmişlik göstermesinin nedeni; kalıp yargılar ve toplumsal cinsiyet rollerinin özellikle kadınlar üzerinde yarattığı iş yükünün etkisi olabilir.

Öğretmenlerin yaşı ile tükenmişlik düzeyleri arasında; duygusal tükenme ve kişisel başarı boyutlarında anlamlı bir farklılık görülmezken; duyarsızlaşma boyutunda 30 yaş ve altındaki öğretmenlerin tükenmişlik düzeyleri, 31-35 yaş grubundaki öğretmenler ile 36-40 yaş grubundaki öğretmenlerin tükenmişlik düzeylerinden anlamlı şekilde daha yüksek bulunmuştur. Bu sonuçlara göre, yaş değişkeninin öğretmenlerin tükenmişlik düzeylerini etkilediği; öğretmenlerin yaşları yükseldikçe olumsuzluklara karşı duyarsılaştıkları söylenebilir. Tükenmişliğin genç öğretmenlerde daha yüksek düzeyde görülmesinin nedeni olarak; mesleğin ilk senelerinin tükenmişlik açısından daha yüksek bir risk taşıması, alınan üniversite eğitimi ile çalışma koşullarının farklı olması, genç öğretmenlerin mesleğin ilk yıllarında daha idealist olmaları ve beklentilerinin daha yüksek olması ve genç öğretmenlerin olumsuzluklarla başa çıkma konusunda daha tecrübesiz olmaları şeklinde yorumlanabilir. Araştırmayla benzer şekilde; Besler (2006) ve Griffin, Hogan, Lambert, TuckerGail ve Baker'ın (2010) öğretmenlerle yaptığı araştırmalarda da yaş değişkeni ile yalnızca duyarsızlaşma boyutu arasında anlamlı farklılıklar bulunmuştur. Ancak; Griffin vd. araştırmasında öğretmenlerin yaşı yükseldikçe duyarsızlaşmanın azaldığı ortaya çıkmıştır. Budak ve Sürgevil (2005), Çavuşoğlu (2005), Yoğun-Erçen (2007), Kayabaşı (2008), Polat vd. (2009), Yıldız (2012), Adiloğulları (2013), Gündoğdu (2013), Demir (2010), Kaya (2010), Uyar ve Erdinç (2011) çalışmalarında yaş ile tükenmişlik düzeyi arasında anlamlı bir ilişki tespit etmemişlerdir.

Öğretmenlerin branşının öğretmenlerin tükenmişliklerinde anlamlı bir farklılık göstermediği tespit edilmiştir. Öğretmenler, hangi branşta görev yaparlarsa yapsınlar, ne kadar yoğun bir tempoda çalışırlarsa çalışsınlar branşları tükenmişlik düzeylerini belirleme de belirleyici bir öge değildir. Kayabaşı (2008), Çağlar ve Demirtaş (2011) ve Bilgen ve Genç (2014) tarafından gerçekleştirilen araştırmalarda da benzer sonuçlara ulaşılmıştır. Öğretmenlerin kıdemlerinin onların tükenmişlerinde anlamlı bir farklılık göstermemiştir. Nitekim Başören (2005), Kayabaşı (2008), Yılmaz (2013), Bilgen ve Genç (2014) tarafından yapılan araştırmalarda da öğretmenlerin mesleki kıdemleri ile tükenmişlik düzeyleri arasında fark anlamlı bulunmamıştır. Ancak Dolunay ve Piyal (2003), Ardıç ve Polatçı (2008), Deniz-Kan (2008), Yı1dız (2012) ve Gündoğdu (2013) yaptıkları araştırmalarda; hizmet süresinin kişisel başarı üzerinde anlamlı farklılık gösterdiğini saptamışlar, toplam hizmet süresi arttıkça kişisel başarı duygusunun artığını tespit etmişlerdir. Fisher (2011) ortaokul öğretmenleri ile gerçekleştirdiği araştırmasında; mesleki kıdem ile tükenmişlik arasında anlamlı fark bulmuştur. 5 yıldan az deneyime sahip öğretmenlerin tükenmişlik düzeylerinin, 5 yıldan fazla deneyime sahip öğretmenlerin tükenmişlik düzeylerinden anlamlı düzeyde daha yüksek olduğunu tespit etmiştir. Darmody ve Smyth'in (2011) araştırmasına göre ise; 1-5 yıl aralığında kıdeme sahip öğretmenlerin tükenmişlik düzeylerinin 20 yıl ve üzeri kıdeme sahip öğretmenlerden anlamlı düzeyde daha düşük olduğu bulunmuştur.

Öğretmenlerin eğitim durumlarının onların tükenmişlik düzeylerinde anlamlı bir farklılık göstermemiştir. Benzer şekilde Çelikkaleli (2011), Demirhan-Harmanda (2011), Yılmaz (2013), Bilgen ve Genç (2014) yaptıkları araştırmalarda öğretmenlerin tükenmişlik düzeyleri ile eğitim durumları arasında anlamlı bir farklılık saptamamışlardır. Ancak Cemaloğlu ve Erdemoğlu-Şahin(2007); Karahan ve Uyanık-Balat(2011) 
Yıldız (2012) ve Gündoğdu'nun (2013) araştırmalarında eğitim durumuna göre tükenmişliğin farklılık gösterdiği tespit edilmiştir. Gündoğdu'nun (2013) araştırmasında; öğretmenlerin eğitim durumları ile tükenmişliğin duygusal tükenme ve kişisel başarı alt boyutları arasında anlamlı bir fark görülmektedir. Araştırma sonuçları incelendiğinde; farkın her iki alt boyutta da doktora ve yüksek lisans yapan öğretmenler arasında ve doktora yapan öğretmenlerin lehine olduğu görülmektedir.

Öğretmenlerin medeni durumları ile tükenmişlikleri arasında; duygusal tükenme ve kişisel başarı boyutlarında anlamlı bir farklılık görülmezken; duyarsızlaşma boyutunda bekâr öğretmenlerin tükenmişlik düzeyleri evli öğretmenlerden anlamlı düzeyde yüksek çıkmıştır. Evlilerin bekarlardan daha az duyarsızlaşmalarının nedeni evlilerinin empati duygularının bekar öğretmenlerinden daha fazla gelişmiş olması ve evliliğin yüklediği sorumluluk bilinci ile yaptıkları işi daha fazla sahiplenmeleri olabilir. Araştırmayla benzer şekilde; Kaya'nın (2014) huzurevlerinde çalışan yaşlı bakım personeli üzerinde yaptığı araştırmada da tükenmişliğin yalnızca duyarsızlaşma alt boyutu ile medeni durumları arasında anlamlı bir farklı1ık saptanmıştır. Başören (2005), Budak ve Sürgevil (2005), Kayabaşı (2008), Otacıoğlu (2008), Yıldız (2012), Çelebi (2013), Yılmaz (2013) ve Bilgen ve Genç (2014) yaptıkları araştırmalarda; medeni durum değişkeni ile tükenmişlik arasında anlamlı bir farklılık saptamamışlardır. Ancak Ardıç ve Polatçı (2008), Demirhan-Harmanda (2011) ve Gündoğdu'nun (2013) araştırmalarına göre; öğretmenlerin medeni durumları ile tükenmişliğin yalnızca kişisel başarı alt boyutu arasında anlamlı fark bulunmaktadır. Üç araştırmanın sonucunda da; evli öğretmenlerin kişisel başarı yönünden tükenmişlik düzeyleri bekâr öğretmenlerden daha yüksektir.

Öğretmenlerin çocuk sayılarının tükenmişlik düzeylerinde anlamlı bir farklılık yaratmadığı bulunmuştur. Budak ve Sürgevil (2005) ve Çelebi'nin (2013) araştırmalarında da benzer sonuçlara ulaşılmıştır. DemirhanHarmanda'nın (2011) araştırmasına göre ise; öğretmenlerin çocuk sayıları ile tükenmişliğin yalnızca kişisel başarı alt boyutu arasında anlamlı fark görülmektedir. 1 çocuğu olan öğretmenlerin kişisel başarı yönünden tükenme düzeyleri, çocuğu olmayan veya 2 ya da daha fazla çocuğu olan gruptaki öğretmenlerin tükenme düzeylerinden daha yüksektir. Benzer bir sonuç da Ardıç ve Polatçı (2008)'nın akademisyenler üzerinde gerçekleştirdiği araştırmada görülmektedir. Araştırmaya göre; 2 çocuk sahibi akademisyenlerin kişisel başarı boyutunda tükenmişlik düzeylerinin çocuk sahibi olmayanlara göre daha fazla olduğu tespit edilmiştir.

Öğretmenlerin görev yaptıkları okuldaki hizmet yılının; onların tükenmişlik düzeylerinde bir farklılık yaratmadığı bulunmuştur. Dolunay ve Piyal (2003), Dilber (2009) ve Çelebi’nin (2013) çalışmalarında da benzer sonuçlara ulaşılmıştır. Ardıç ve Polatçı'nın (2008) akademisyenler üzerinde gerçekleştirdiği araştırmaya göre ise; görev yapılan okuldaki çalışma süreleri incelendiğinde yalnızca kişisel başarı alt boyutu açısından farklılaşma gözlenmiştir. 21 yıl ve üzeri aynı okulda görev yapanların, işe yeni başlayanlara göre daha yüksek düzeyde kişisel başarı sergiledikleri tespit edilmişsir. Yılların verdiği tecrübe ve bilgi birikimi kişisel başarı kazanmalarında etkili olmuş olabilir.

Öğretmenlerin görev yaptıkları okulun sosyo-ekonomik durumunun tükenmişlik düzeylerinde anlamlı bir farklılık yaratmadığı tespit edilmiştir. Darmody ve Smyth'in (2011) araştırmasında da benzer sonuçlara ulaşılmıştır. Yıldız'ın (2012) araştırmasına göre ise; sosyo-ekonomik düzeyi düşük yerlerde çalışan rehber öğretmenler, sosyo ekonomik düzeyi yüksek yerlerde çalışan rehber öğretmenlere göre kişisel başarı boyutunda anlamlı düzeyde daha fazla tükenmişlik yaşamaktadırlar. Goswami'nin (2013) ortaokul öğretmenleri ile gerçekleştirdiği araştırmada; okulun sosyo-ekonomik durumunun öğretmenlerin duygusal tükenme ve duyarsızlaşma boyutları üzerinde anlamlı şekilde etkili olduğu saptanmış ancak kişisel başarı boyutu üzerinde anlamlı bir etkisi görülmemiştir. 
Mesleğini kendi isteği ile seçip seçmeme değişkenine göre öğretmenlerin tükenmişlik düzeylerinde; duyarsızlaşma ve kişisel başarı boyutlarında anlamlı bir fark ortaya çıkmazken; mesleğini istemeyerek seçen öğretmenlerin duygusal tükenme düzeylerinin, mesleğini isteyerek seçen öğretmenlere göre anlamlı düzeyde daha yüksek olduğu saptanmıştır. Mesleğini istemeyerek seçen öğretmenlerin işleri ile bütünleşmemeleri, işlerini severek yapmamaları ve yaptıklarındanda mutluluk duymamaları mesleği isteyerek seçen öğretmenlerden daha fazla duygusal tükenme göstermelerinin nedenleri olabilir. Dolunay ve Piyal (2003), Cemaloğlu ve Erdemoğlu-Şahin (2007) ve Dilber'in (2009) araştırmalarına göre; öğretmenlerin mesleği isteyerek seçip seçmeme durumları ile tükenmişliğin duygusal tükenme, duyarsızlaşma ve kişisel başarı boyutları arasındaki fark anlamlı bulunurken; Özben ve Argun (2003), Otacığlu (2008) ve Yılmaz'ın (2013) araştırmalarındaki fark anlamlı bulunmamıştır.

Ortaokul öğretmenlerinin görece en çok içsel doyum sağladığı, bunu sırasıyla genel ve dışsal doyumun takip ettiği bulunmuştur. Öğretmenlerin içsel, dişsal ve genel iş doyumu düzeyleri "memnunum" düzeyindedir. Arık'ın (2010) çalışmasında da benzer sonuçlara ulaşılmıştır. Öğretmenlerin maaşlarının düşük olması ve bu nedenle öğretmenlerin geçim sıkıntısı çekmeleri, düzenli işleyen bir terfi sisteminin bulunmaması, düzenlenen ödül ve terfi sistemlerinin objektif ve güvenilir bir şekilde yapılmaması ve süreklilik arz etmemesi öğretmenlerin dışsal iş doyum düzeylerinin düşük olmasında etkili olabilir.

Öğretmenlerin cinsiyetlerinin iş doyumunda anlamlı bir farklılık yaratmadığı ortaya çıkmıştır. Avşaroğlu, Deniz ve Kahraman (2005), Göktaş (2007), Taşdan ve Tiryaki (2008), Karataş ve Güleş (2010), Adıgüzel, Karadağ ve Ünsal (2011), Çağlar ve Demirtaş (2011), Yılmaz ve Ceylan (2011), Nagar (2012), Gündoğdu (2013), Koruklu, Feyzioğlu, Özenoğlu-Kiremit ve Aladağ (2013) ve Raj ve Lalita (2013) çalışmalarında benzer sonuçlara ulaşmışlardır. Ancak Darmody ve Smyth (2011) çalışmalarında kadın öğretmenlerin iş doyum düzeylerinin erkek öğretmenlerden anlamlı düzeyde yüksek olduğunu tespit etmişlerdir.

Öğretmenlerin yaşlarının iş doyumunda anlamlı bir farklılık yaratmadığı ortaya çıkmıştır. Avşaroğlu, Deniz ve Kahraman (2005), Adıgüzel, Karadağ ve Ünsal (2011) ve Nagar (2012) çalışmalarında da benzer sonuçlara ulaşılmıştır. Göktaş (2007), Karataş ve Güleş (2010), Darmody ve Smyth'in (2011), Gündoğdu (2013) ve Koruklu, Feyzioğlu, Özenoğlu-Kiremit ve Aladağ'ın (2013) araştırmalarında ise; öğretmenlerin yaşına göre iş doyumlarının farklılık gösterdiği bulunmuştur. Darmody ve Smyth'in (2011) araştırmasında ise; genç öğretmenlerin yaşlilara göre daha yüksek iş doyumuna sahip olduğu bulunmuştur.

Öğretmenlerin iş doyumu düzeyleri branş değişkenine göre anlamlı bir farklılık göstermemektedir. Çağlar ve Demirtaş (2011), Koruklu, Feyzioğlu, Özenoğlu-Kiremit ve Aladağ'ın (2013) araştırmalarında da benzer sonuçlara ulaşılmıştır. Yılmaz ve Ceylan'ın (2011) araştırmasında ise öğretmenlerin branşlarının onların iş doyum düzeylerinde farklılık yarattığ tespit edilmiştir.

Öğretmenlerin kıdemine göre; iş doyumlarında anlamlı bir farklılık saptanmamıştır. Avşaroğlu, Deniz ve Kahraman (2005), Göktaş (2007), Taşdan ve Tiryaki (2008), Adıgüzel, Karadağ ve Ünsal (2011), Y1lmaz ve Ceylan (2011), Koruklu, Feyzioğlu, Özenoğlu-Kiremit ve Aladağ (2013) ve Yılmaz ve Kıral'ın (2014) çalışmalarında da benzer sonuçlara ulaşılmıştır. Gündoğdu'nun (2013) araştırmasında ise; öğretmenlerin kıdemleri ile iş doyumu ortalamaları arasında anlamlı farklılık bulunmuştur. En yüksek iş doyumu, 21-25 yıl kıdemi olan öğretmenlerde görülmüş̧ür. Darmody ve Smyth'in (2011) araştırmasına göre de öğretmenlerin mesleki kıdemleri ile iş doyumları arasında anlamlı bir ilişki görülmektedir. İșe yeni başlayan öğretmenlerin (son 5 yıl içinde atananlar) iş doyumu düzeylerinin, daha fazla mesleki kıdeme sahip öğretmenlerin iş doyumu düzeylerinden daha yüksek olduğu tespit edilmiştir. 
Öğretmenlerin iş doyumu düzeyleri eğitim durumu değişkenine göre anlamlı bir farklılık göstermemektedir. Taşdan ve Tiryaki (2008) ve Koruklu, Feyzioğlu, Özenoğlu-Kiremit ve Aladağ’ın (2013) öğretmenler üzerinde yaptıkları çalışmalarda da benzer sonuçlara ulaşılmıştır. Yine farklı alanlarda (otel, hastane, banka, gıda, muhasebe vb.); Yılmaz ve Karahan (2009), Demir (2010), Sat (2011), Tor (2011), Uyar ve Erdinç (2011) tarafindan yapılan çalışmalarda da benzer sonuçlar ortaya çıkmıştır. Adıgüzel, Karadağ ve Ünsal'ın (2011) araştırmasında; Fen ve Teknoloji öğretmenlerinin iş doyumu puanlarının eğitim durumu değişkenine göre, yüksek lisans yapan öğretmenler lehine anlamlı bir fark bulunmuştur. Toker'in (2007) araştırmasında ise; özellikle lise mezunu çalışanlarla üniversite mezunu çalışanlar arasında iş doyumu bakımından anlamlı düzeyde bir farklılık olduğu belirlenmiştir. Gündoğdu'nun (2013) araştırmasında da öğretmenlerin eğitim durumları ile iş doyumu ortalamaları arasındaki fark anlamlı bulunmuştur. Araştırma sonucuna göre; doktora yapan öğretmenlerin ortalamaları özellikle yüksek lisans yapan öğretmenlerden daha yüksek bulunmuştur.

Öğretmenlerin iş doyumu düzeyleri medeni durum değişkenine göre anlamlı bir farklılık göstermemektedir. Adıgüzel, Karadağ ve Ünsal (2011) yaptıkları çalışmada benzer sonuçlara ulaşmışlardır. Yine farklı alanlarda (otel, hastane, banka, gida, muhasebe vb.) Toker (2007), Yılmaz ve Karahan (2009), Demir (2010), Sat (2011), Tor (2011) ve Uyar ve Erdinç (2011) de iş doyumu ile medeni durum arasında anlamlı farklılık saptamamışlardır. Gündoğdu (2013) tarafından yapılan araştırmada ise; öğretmenlerin medeni durumları ile iş doyumları arasında anlamlı farklılık görülmüştür. Buna göre; evli öğretmenlerin iş doyumu ortalamaları bekâr öğretmenlere göre daha yüksektir. Araştırma sonucuna dayanarak; evliliğin, kişinin işle ilgili düşüncelerini olumlu yönde etkilediği söylenebilir.

Öğretmenlerin iş doyumu düzeyleri çocuk sayısı değişkenine göre anlamlı bir farklılık göstermemektedir. Adıgüzel, Karadağ ve Ünsal'ın (2011) öğretmenler üzerinde ve Tor'un (2011) gıda sektöründe çalışanlar üzerinde gerçekleştirdiği çalışmaların sonuçları da araştırmayı destekler niteliktedir. Öğretmenlerin görev yaptığı okuldaki hizmet yılına göre iş doyumlarında anlamlı bir farklılık bulunmamıştır. Araştırmayı destekler nitelikte; Türkoğlu (2008) ve Yılmaz ve Kıral'ın (2014) öğretmenler üzerinde yaptıkları araştırmalarda da görev yaptığı okuldaki hizmet yılı ile iş doyumu arasında anlamlı bir fark bulunmamıştır.

Öğretmenlerin görev yaptıkları okulun sosyo-ekonomik durumu ile iş doyumları arasında; içsel ve genel doyum boyutlarında anlamlı bir farklılık saptanmazken; dışsal doyum boyutunda anlamlı bir farklılık saptanmıştır. Bu sonuca göre, bulundukları okulun sosyo-ekonomik durumu düşük olan öğretmenlerin dışsal boyuttaki iş doyumu düzeyleri, bulundukları okulun sosyo-ekonomik durumu orta olan öğretmenlerden daha düşüktür. Bunda öğretmenlerin yaptıklarının çevre tarafından takdir edilmemesi, işbirliği içerisinde çalışamaması gibi nedenler etkili olmuş olabilir. Koruklu, Feyzioğlu, Özenoğlu-Kiremit ve Aladağ’ın (2013) araştırmasında da; ögretmenlerin iş doyum düzeylerinin çalışılan okulun sosyo-ekonomik durumuna göre anlamlı farklılık gösterdiği bulunmuştur. Çalıştıkları kurumun sosyo-ekonomik durumunu yeterli bulan öğretmenlerin iş doyumu düzeylerinin, yetersiz bulanlara göre anlamlı düzeyde daha yüksek olduğu tespit edilmiştir. George, Louw ve Badenhorst'un (2008) araştırmasına göre de; okulun sosyo-ekonomik durumu ile öğretmenlerin içsel, dışsal ve genel iş doyum düzeyleri arasında anlamlı farklılık bulunmaktadır. Araştırmaya göre; bulundukları okulun sosyo-ekonomik durumu ortalamanın üzerinde olan öğretmenlerin içsel, dişsal ve genel iş doyumu düzeyleri, okullarının sosyo-ekonomik durumu ortalamanın altında bulunan öğretmenlerden anlamlı düzeyde yüksek bulunmuştur.

Mesleğini kendi isteği ile seçen öğretmenlerin iş doyum düzeyleri hem boyutlar bazında hem de genel olarak mesleğini kendi isteği seçmeyen öğretmenlerden anlamlı şekilde yüksek bulunmuştur. Öğretmenlerin mesleğini isteyerek severek yapması ve bu işten haz alması dolayısı ile kendini bu mesleğe adamasına ve yaptığı işten doyum sağlamasına yol açmış olabilir. Yılmaz ve Kıral'ın (2014) araştırmasında; öğretmenlerin 
içsel ve dişsal doyum düzeyleri, mesleklerini isteyerek seçip seçmeme durumlarına göre anlamlı bir farklılık göstermemiş ancak genel iş doyumu düzeyleri anlamlı bir fark göstermiştir. Araştırma sonucunda; mesleğini kendi isteğiyle seçen öğretmenlerin genel iş doyumu düzeyleri, mesleğini istemeyerek seçenlerden anlaml 1 düzeyde yüksek bulunmuştur. Türkçapar'ın (2012) araştırmasında ise; öğretmenlerin mesleklerini isteyerek seçip seçmemeleri ile iş doyumları arasında anlamlı bir ilişki saptanmamıştır.

Öğretmenlerin içsel iş doyumları ile dışsal iş doyumları arasında orta; genel iş doyumları arasında yüksek düzeyde pozitif yönde anlamlı ilişkiler bulunmuştur. Öğretmenlerin içsel iş doyumları ile duygusal tükenmeleri, kişisel başarıları ve duyarsızlaşmaları arasında negatif yönde orta düzeyde anlamlı ilişkiler ortaya çıkmıştır. Öğretmenlerin dışsal iş doyumları ile genel iş doyumları arasında yüksek düzeyde pozitif yönde anlamlı bir ilişki bulunmuştur. Öğretmenlerin dışsal iş doyumları ile duygusal tükenmeleri arasında orta, duyarsızlaşmaları ve kişisel başarıları arasında düşük düzeyde negatif yönde anlamlı ilişkiler bulunmuştur. Öğretmenlerin genel iş doyumları ile duygusal tükenmeleri, duyarsızlaşmaları ve kişisel başarıları arasında orta düzeyde negatif yönde anlamlı ilişkiler bulunmuştur. Öğretmenlerin duygusal tükenmeleri ile duyarsızlaşmaları ve kişisel başarıları arasında orta düzeyde pozitif yönde anlamlı ilişkiler saptanmıştır. Öğretmenlerin duyarsızlaşmaları ile kişisel başarıları arasında ise orta düzeyde pozitif yönde anlamlı bir ilişki bulunmuştur.

Griffin ve diğerlerinin (2010) araştırmasında da; iş doyumu ile duygusal tükenme, duyarsızlaşma ve kişisel başarısızlık arasında orta düzeyde negatif yönde anlamlı ilişkiler bulunmuştur. Tükenmişliğin boyutları ise birbirleri ile orta düzeyde pozitif yönde anlamlı ilişkiler göstermişlerdir. Gündoğdu'nun (2013) araştırmasına göre; öğretmenlerin duygusal tükenme düzeyleri ile iş doyumu düzeyleri arasında anlamlı ve negatif yönlü bir ilişki bulunurken, kişisel başarı düzeyleri ile iş doyumu düzeyleri arasında anlamlı ve pozitif yönlü bir ilişki bulunmaktadır. Öğretmenlerde duygusal tükenme azaldıkça iş doyumunun artacağı ve kişisel başarı duygusunun artmasıyla iş doyumunun artacağı söylenebilir. George, Louw ve Badenhorst'un (2008) araştırmasında; tükenmişliğin duygusal tükenme ve duyarsızlaşma boyutları ile içsel ve dışsal iş doyumları arasında negatif yönde; kişisel başarı boyutu ile içsel ve dışsal doyumları arasında ise pozitif yönde anlamlı ilişkiler bulunmuştur. Goswami'nin (2013) araştırmasında da; tükenmişliğin tüm alt boyutları ile iş doyumu arasında anlamlı ilişkiler tespit edilmiştir. Duygusal tükenme ve duyarsızlaşma boyutları ile iş doyumu arasında negatif yönde; kişisel başarı ile iş doyumu arasında pozitif yönde anlamlı ilişkiler bulunmuştur. İş doyumu düşük öğretmenlerin duygusal tükenme ve duyarsızlaşma düzeyleri anlamlı biçimde artmaktadır. İş doyumları düşük öğretmenlerin kişisel başarılarının da düşük olduğu bulunmuştur. Duygusal tükenme ve duyarsızlaşma boyutları ile içsel doyum arasında negatif yönde; kişisel başarı ile içsel doyum arasında pozitif yönde anlamlı bir ilişkiler saptanmıştır. Chenevey, Ewing ve Whittington'ın (2008) araştırmasında ise iş doyumu ile duygusal tükenme arasında düşük düzeyde pozitif bir ilişki bulunmuştur.

Öğretmenlerin duygusal tükenmişliklerinin; içsel ve dışsal iş doyumu tarafından anlamlı bir biçimde yordandığı bulunmuştur. Hem içsel doyum hem de dışsal doyum, duygusal tükenmenin anlamlı birer yordayıcısıdır. Öğretmenlerin içsel ve dışsal doyumları arttıkça duygusal tükenmeleri görece önemli ölçüde azalmaktadır. Öğretmenlerin etkili ve verimli bir şekilde çalışmaları yani tükenmemeleri, işlerinde doyum sağlamalarına bağlı olabilir. Çünkü öğretmenlerin yaşadığı iş doyumu, onların iş dışındaki sosyal hayatlarını, fizyolojik ve psikolojik sağlıklarını ve verimliliklerini de etkilemektedir. Duygusal tükenmişliğin en güçlü ilişkiyi içsel doyumla göstermesi öğretmenlerin; başarı, takdir edilme, ödül alma, kabul edilme, terfi ve gelişme olanakları gibi etkenlere; ücret, statü, iş güvencesi, yönetici davranışları, meslektaşlarla ilişkiler, iş ortamının fiziksel şartları gibi etmenlerden daha çok önem verdiklerinin göstergesi olarak algılanabilir. Ertürk ve Keçecioğlu (2012) yaptıkları araştırmada benzer sonuçlara ulaşmışlar; iş doyum düzeyinin artmasının duygusal tükenmişlik düzeyinin azalmasına neden olduğunu tespit etmişlerdir. Gündüz, Çapri ve 
Gökçakan'ın (2013) farklı mesleklerden seçilen gönüllü çalışanlarla yaptığı araştırmasında da; genel iş doyumunun, tükenmişliğin duygusal tükenme alt boyutunu anlamlı düzeyde yordadığı görülmektedir.

Öğretmenlerin duyarsızlaşmalarının; içsel ve dışsal iş doyumu boyutlarının doğrusal kombinasyonu tarafından anlamlı bir biçimde yordandığı bulunmuştur. Ancak içsel doyumun duyarsızlaşmanın anlamlı bir yordayıcısı olduğu tespit edilirken, dışsal doyumun duyarsızlaşmanın anlamlı bir yordayıcısı olmadığı ortaya çıkmıştır. Öğretmenlerin içsel doyumu arttıkça duyarsızlaşmalarının görece önemli ölçüde azaldığı tespit edilmiştir. Buna göre öğretmenlerin duyarsızlığını; sınıf mevcutlarının fazla olması, okulun fiziki imkânlarının yetersiz olması, maaşlarının düşük olması gibi dışsal doyum etmenlerinin etkilemediği söylenebilir. Yavaş'ın (2007) çalışmasında da içsel doyumun, tükenmişliğin özellikle duyarsızlaşma boyutunun anlamlı yordayıcısı olduğu tespit edilmiştir. Bunun da sebebi olarak, toplumun ve öğrenci velilerinin eleştirileri ve öğretmenlerin takdir edilmemesi olduğunu ifade etmiştir. Gündüz, Çapri ve Gökçakan'ın (2013) farklı mesleklerden seçilen gönüllü çalışanlarla yaptığı araştırmalarında da genel iş doyumunun duyarsızlaşmayı anlamlı düzeyde yordadığını saptamışlardır.

Öğretmenlerin kişisel başarılarının; içsel ve dışsal iş doyumu boyutlarının doğrusal kombinasyonu tarafindan anlamlı bir biçimde yordandığı bulunmuştur. Ancak içsel doyumun kişisel başarının anlamlı bir yordayıcısı olduğu tespit edilirken, dışsal doyumun kişisel başarının anlamlı bir yordayıcısı olmadığı tespit edilmiştir. Öğretmenlerin içsel doyumları arttıça kişisel başarızlıklarının önemli ölçüde azaldığı bulunmuştur. Öğretmenlerin kişisel başarılarının sadece içsel doyum boyutu tarafından yordanmasının nedeni; öğretmenlerin bir sorunu başarı ile atlatma ve bunun sonucunda da kendilerini yeterli bulmaları ve kendilerine olan saygılarının artması olarak kabul edilebilir. Watts'ın (2013) çalışmasında; genel iş doyumunun, tükenmişliğin duygusal tükenme ve duyarsızlaşma boyutlarını negatif yönde; kişisel başarı boyutunu ise pozitif yönde anlamlı şekilde yordadığı bulunmuştur. Gündüz, Çapri ve Gökçekan'ın (2013) araştırmasında da benzer şekilde; genel iş doyumunun, duygusal tükenme ve duyarsılaşma alt boyutlarını negatif yönde, kişisel başarıyı boyutunu ise pozitif yönde ve anlamlı düzeyde yordadığı saptanmıştır

Öğretmenlerin tükenmişlikleri ile iş doyumları arasında anlamlı ilişkiler saptanmıştır. İş doyumunun tükenmişliğin anlamlı yordayıcı olduğu bulunmuştur. Mesleki tükenmişlik yaşayan bir öğretmenin işinde mutlu olmamakta bu da onun işinde doyumsuzluk yaşamasına neden olmaktadır. Bu nedenle, öğretmenlik mesleğini seçecek olan kişilere, bu mesleğin gerektirdiği yetenek ve beceriler ile taşıdığı riskler tanıtılmalı ve onların daha iyi seçim yapmalarına imkan verilmelidir. Ortaokul çağından başlanarak, öğrenciler ilgi ve yetenekleri doğrultusunda uygun meslek seçimine yönlendirilmeli ve bu süreçte uygun rehberlik çalışmaları yapılmalıdır. Nitekim bilinçli ve isteyerek seçilen ve severek yapılan bir işten elde edilen doyum arttıkça, tükenmişlik de azalabilir. Öğretmenlerin iş doyumlarını artırmaya yönelik çalışmalar (özlük hakkı, örgüt kültürü vb) yapılabilir. Kadın öğretmenlerin kişisel başarısızlık boyutundaki tükenmişlikleri erkek öğretmenlerden yüksek bulunmuştur. Cinsiyet rollerinin olumsuz etkilerinden ve yarattı̆̆ yükten kurtulmak için cinsiyet rolleri sorgulanmalı ve cinsiyetlerin eşit haklara sahip olduğuna ilişkin ailelere eğitim verilmelidir. Sosyo-ekonomik durumu düşük olan okullardaki yöneticiler; öğretmenlerin olumlu davranışlarını takdir etmekten kaçınmamalı, onları desteklemeli ve motive etmelidir. Milli Eğitim Müdürlüğü de okullar arasındaki imkân eşitsizliklerini gidermek için çalışmalar yapmalıdır. Bu çalışma iş doyumu ve tükenmişlik düzeyleri demografik değişkenlerlere göre tek değişkenli analiz tekniği ile incelenmiştir. Sonraki çalışmalarda bu değişkenler çok değişkenli analiz teknikleri ile farklı araştırmacılar tarafından incelenebilir. Söz konusu çalışma kesitsel bir çalışma olup, daha güvenilir sonuçlar için boylamsal çalışmalara da ihtiyaç vardır. 


\section{Kaynaklar}

Adıgüzel, Z., Karadağ, M. ve Ünsal, Y. (2011). Fen ve teknoloji öğretmenlerinin iş tatmin düzeylerinin bazı değişkenlere göre incelenmesi. Batı Anadolu Ĕ̈itim Bilimleri Dergisi, 2 (4), 49-74.

Adiloğulları, G. E. (2013). Beden eğitimi ögretmenlerinin duygusal zekâ ile mesleki tükenmişlik düzeyleri arasındaki ilişkinin incelenmesi. Yayımlanmamış Yüksek Lisans Tezi. Kahramanmaraş Sütçü İmam Üniversitesi Sağlık Bilimleri Enstitüsü Beden Eğitimi ve Spor Ana Bilim Dalı: Kahramanmaraş.

Akıncı, Z. (2002). Turizm sektöründe işgören iş tatminini etkileyen faktörler: Beş yıldızlı konaklama işletmelerinde bir uygulama. Akdeniz Üniversitesi İktisadi ve İdari Bilimler Fakültesi Dergisi, 4, 125 .

Ardıç, K. ve Polatçı, S. (2008). Tükenmişlik sendromu akademisyenler üzerinde bir uygulama (GOÜ Örneği). Gazi Üniversitesi İktisadi ve İdari Bilimler Fakültesi Dergis, 10 (2), 69-96.

Arık, İ. (2010). T.C. Milli Eğitim Bakanlı̆ğ’nın yurtdışına görevlendirdiği öğretmenlerin iş doyumu (Kırgızistan Örneği). Yayımlanmamış Yüksek Lisans Tezi. Kırgızistan-Türkiye Manas Üniversitesi Sosyal Bilimler Enstitüsü Eğitim Bilimleri Anabilim Dalı: Bişkek.

Avşaroğlu, S., Deniz, M. E. ve Kahraman, A. (2005). Teknik öğretmenlerde yaşam doyumu, iş doyumu ve mesleki tükenmişlik düzeylerinin incelenmesi. Selçuk Üniversitesi Sosyal Bilimler Enstitüsü Dergisi, $14,115-129$.

Aydemir, H. (2013). Özel eğitim alanında çalışan ögretmenlerin tükenmişlik düzeyleri ve yaşam doyumlarının incelenmesi. Yayımlanmamış Yüksek Lisans Tezi. Abant İzzet Baysal Üniversitesi Eğitim Bilimleri Enstitüsü Özel Eğitim Ana Bilim Dalı: Bolu.

Balc1, A. (2009). Sosyal bilimlerde araştırma yöntem, teknik ve ilkeler. Ankara: Pegem Akademi.

Barutçu, E. ve Serinkan, C. (2008). Günümüzün önemli sorunlarından biri olarak tükenmişlik sendromu ve Denizli’de yapılan bir araştırma. Ege Akademik Bakış, 8 (2), 541-561.

Başol, G. ve Altay, M. (2009). Eğitim yöneticisi ve öğretmenlerin mesleki tükenmişlik düzeylerinin incelenmesi. Kuram ve Uygulamada Eğitim Yönetimi, 15 (58), 191-216.

Başören, M. (2005). Çeşitli değişkenlere göre rehber öğretmenlerinin tükenmişlik düzeylerinin incelenmesi (Zonguldak İli Örneği). Yayımlanmamış Yüksek Lisans Tezi. Karaelmas Üniversitesi Sosyal Bilimler Enstitüsü Eğitim Programları ve Öğretim Anabilim Dalı: Zonguldak.

Baycan, A. (1985). Analiysis of several aspects of job satisfaction between different occupational groups. Yayımlanmamış Yüksek Lisans Tezi. Boğaziçi Üniversitesi Sosyal Bilimler Enstitüsü: İstanbul.

Besler, E. (2006). Mesleki ve teknik eğitim kurumlarında görev yapan öğretmenlerde tükenmişliğin incelenmesi. Yayımlanmamış Yüksek Lisans Tezi. Marmara Üniversitesi Fen Bilimleri Enstitüsü Teknoloji Eğitimi Anabilim Dalı Teknoloji Eğitimi Programı: İstanbul. 
Bilgen, S. ve Genç, S. Z. (2014). The Rate of burnout of elementary school teachers and elementary mathematics teachers. Educational Research Association, The International Journal of Educational Researchers. 5 (1), 1-9.

Budak, G. ve Sürgevil, O. (2005). Tükenmişlik ve tükenmişliği etkileyen örgütsel faktörlerin analizine ilişkin akademik personel üzerinde bir uygulama. Dokuz Eylül Üniversitesi Iktisadi ve İdari Bilimler Fakültesi Dergisi, 20 (2), 95-108.

Büyüköztürk, Ş. (2016). Sosyal bilimler için veri analizi el kitabı. Ankara: PegemA Akademi.

Can, A. (2016). SPSS ile bilimsel araştırma sürecinde veri analizi. Ankara:PegemA Akademi.

Cemaloğlu, N. ve Erdemoğlu-Şahin, D. (2007). Öğretmenlerin mesleki tükenmişlik düzeylerinin farklı değişkenlere göre incelenmesi. Kastamonu Ĕgitim Dergisi, 15 (2), 465-484.

Cemaloğlu, N. ve Kayabaşı, Y. (2007). Öğretmenlerin tükenmişlik düzeyi ile sınıf yönetiminde kullandıkları disiplin modelleri arasındaki ilişki. Gazi Üniversitesi Ĕgitim Fakültesi Dergisi, 27 (2), 123-155.

Chenevey, J. L., Ewing, J. C. ve Whittington M. S. (2008). Teacher burnout and job satisfaction among agricultural education teachers. Journal of Agricultural Education. 49 (3), 12-22.

Çağlar, Ç. ve Demirtaş, H. (2011). Dershane öğretmenlerinde tükenmişlik ve iş doyumu. E-Uluslararası Ĕ̈itim Araştırmaları Dergisi. 2 (2), 30-49.

Çağlıyan, Y. (2007). Tükenmişlik sendromu ve iş doyumuna etkisi (Devlet ve Vakıf üniversitelerindeki akademisyenlere yönelik alan araştırması). Yayımlanmamış Yüksek Lisans Tezi. Kocaeli Üniversitesi Sosyal Bilimler Enstitüsü Çalışma Ekonomisi Anabilim Dalı: Kocaeli.

Çam, O. (1992). Tükenmişlik envanterinin geçerlik ve güvenirliğinin araştırılması. 7. Ulusal Psikoloji Kongresi Bilimsel Çalışmaları El Kitabı. Ankara: Psikologlar Derneği Yayınları.

Çapri, B. (2006). Tükenmişlik ölçeğinin türkçe uyarlaması: Geçerlik ve güvenirlik çalışması. Mersin Üniversitesi Ë̆itim Fakültesi Dergisi. 2 (1), 62-77.

Çavuş, M. F., Gök, T. ve Kurtay, F. (2007). Tükenmişlik: Meslek yüksekokulu akademik personeli üzerine bir araştırma. Çukurova Üniversitesi Sosyal Bilimler Enstitüsü Dergisi. 16 (2), 97-108.

Çavuşoğlu, İ. (2005). Endüstri meslek liselerinde çalışan öğretmenlerin tükenmişlik düzeyleri ile bazı kişisel değişsenlerin arasındaki iliş̧ki (Bolu İli Örneği). Yayımlanmamış Yüksek Lisans Tezi. Abant İzzet Baysal Üniversitesi Sosyal Bilimler Enstitüsü Eğitim Bilimleri Anabilim Dalı Eğitim Yönetimi ve Denetimi Bilim Dalı: Bolu.

Çelebi, E. (2013). Elazı̆̆ ve Malatya il merkezinde bulunan özel ĕgitim kurumlarında çalışan öğretmenlerin tükenmişlik düzeyleri ve ilgili faktörler. Yayımlanmamış Doktora Tezi. Fırat Üniversitesi Hemşirelik Anabilim Dalı: Elazı̆̆.

Çelikkaleli, Ö. (2011). Yetişkin eğitimcisi öğretmenlerin tükenmişlik ve mesleki yetkinliklerinin incelenmesi. Mehmet Akif Ersoy Üniversitesi Sosyal Bilimler Enstitüsü Dergisi, 3 (4), 38-53. 
Darmody, M. ve Smyth, E. (2011). Job satisfaction and occupational stress among primary school teachers and school principals in Ireland. ESRI / The Teaching Council: Dublin, Ireland.

Demir, S. (2010). Ankara üniversitesi tıp fakültesi hastaneleri çalışanlarının tükenmişlik ve iş doyumu düzeylerinin bazı değisskenler açısından incelenmesi. Yayımlanmamış Yüksek Lisans Tezi. Atılım Üniversitesi Sosyal Bilimler Enstitüsü Sağlık Kurumları İşletmeciliği Anabilim Dalı: Ankara.

Demirdöğen, N. (2013). Okul öncesi ögretmenlerinin tükenmişlik düzeyleri ile psikolojik yardım arayışları arasındaki ilişkinin incelenmesi. Yayımlanmamış Yüksek Lisans Tezi. Yeditepe Üniversitesi Sosyal Bilimler Enstitüsü Eğitim Yönetimi ve Denetimi Yüksek Lisans Programı: İstanbul.

Demirhan-Harmanda, E. (2011). Ankara il merkezinde görev yapan okul öncesi eğitimi ögrretmenlerinin tükenmişlik düzeyleri ile çocuklarda görülen istenmeyen davranışları değerlendirmeleri arasındaki ilişkinin incelenmesi. Yayımlanmamış Yüksek Lisans Tezi. Gazi Üniversitesi, Eğitim Bilimleri Enstitüsü Çocuk Gelişimi ve Eğitimi Anabilim Dalı: Ankara.

Deniz-Kan, Ü. (2008). Bir grup okul öncesi öğretmeninde tükenmişlik durumunun incelenmesi. Kastamonu Ĕ̈itim Dergisi, 16 (2), 431-438.

Dilber, E. (2009). İlköğretim ögretmenlerinin tükenmişlik yaşantıları ve yeterlik algıları: istanbul kartal ilçesi örneği. Yayımlanmamış Yüksek Lisans Tezi. Beykent Üniversitesi Sosyal Bilimler Enstitüsü İşletme Yönetimi Anabilim Dalı Eğitim Yönetimi ve Denetimi Bilim Dalı: İstanbul.

Dolunay, A. B. (2002). Keçiören ilçesi genel liseler ve teknik-ticari-meslek liselerinde görevli öğretmenlerde tükenmişlik durumu araştırması. Ankara Üniversitesi Tıp Fakültesi Mecmuası. 55 (1), 51-62.

Dolunay, A. B. ve Piyal, B. (2003). Öğretmenlerde bazı mesleki özellikler ve tükenmişlik. Kriz Dergisi, 11 (1), 35-48.

Ergin, C. (1992). Doktor ve hemşirelerde tükenmişlik ve maslach tükenmişlik ölçeğinin uyarlanması. VII. Ulusal Psikoloji Kongresi Bilimsel Çalışmaları, 22, 25.

Erkul, A. ve Dalgıç, G. (2014). Meslek lisesi öğretmenlerinin mesleki tükenmişlik düzeylerinin incelenmesi. Ĕ̈itim Bilimleri Araştırma Dergisi Uluslararası E-Dergi, 4 (2), 1-18.

Ertürk, E. ve Keçecioğlu, T. (2012). Çalışanların iş doyumları ile mesleki tükenmişlik düzeyleri arasındaki ilişkiler: Öğretmenler üzerine örnek bir uygulama. Ege Akademik Bakış, 12 (1), 39-52.

Fisher, M. H. (2011). Factors influencing stress, burnout, and retention of secondary teachers. Current Issues in Education. 14 (1).

George, E., Louw, D. ve Badenhorst, G. (2008). Job satisfaction among urban secondary-school teachers in Namibia. South African Journal of Education Copyright, 28, 135-154.

Goswami, M. (2013). A study of burnout of secondary school teachers in relation to their job satisfaction. IOSR Journal of Humanities and Social Science (IOSR-JHSS), 10 (1), 18-26.

Göktaş, Z. (2007). Balıkesir İlindeki Beden Eğitimi Öğretmenlerinin İş Doyumu ve Bazı Değişkenlerle Olan İlişkisinin İncelenmesi. Niğde Üniversitesi Beden Eğitimi ve Spor Bilimleri Dergisi, 1 (1), 13-25. 
Griffin, M. L., Hogan, N. L., Lambert, E. G., Tucker-Gail, K. A. ve Baker, D. N. (2010). Job involvement, job stress, job satisfaction, and organizational commitment and the burnout of correctional staff. Criminal Justice and Behavior. 37 (2), 239-255.

Gündoğdu, G. B. (2013). Sınıf ögretmenlerinin iş doyumu ve mesleki tükenmişlik düzeyleri üzerine bir çalışma: Mersin ili örneği. Yayımlanmamış Yüksek Lisans Tezi. Çağ Üniversitesi Sosyal Bilimler Enstitüsü İşletme Yönetimi Anabilim Dalı: Mersin.

Gündüz, B. (2005). İlköğretim öğretmenlerinde tükenmişlik. Mersin Üniversitesi Eğitim Fakültesi Dergisi, 1 (1), 152-166.

Gündüz, B., Çapri, B. ve Gökçakan, Z. (2013). Mesleki tükenmişlik, işle bütünleşme ve iş doyumu arasındaki ilişkilerin incelenmesi. Eğitim Bilimleri Araştırmaları Dergisi Uluslararası E-Dergi, 3 (1), 29-49.

Izgar, H. (2000). Okul yöneticilerinin tükenmişlik düzeyleri (burnout), nedenleri ve bazı etken faktörlere göre incelenmesi (Orta Anadolu Örneği). Yayımlanmamış Doktora Tezi. Selçuk Üniversitesi Sosyal Bilimler Enstitüsü Eğitim Bilimleri Ana Bilim Dalı Eğitimde Psikolojik Hizmetler Bilim Dalı: Konya.

Karahan, Ş. ve Uyanık-Balat, G. (2011). Özel eğitim okullarında çalışan eğitimcilerin öz-yeterlik algılarının ve tükenmişlik düzeylerinin incelenmesi. Pamukkale Üniversitesi Eğitim Fakültesi Dergisi, 29 (1), $1-14$.

Karakelle, S. ve Canpolat, S. (2008). Tükenmişlik düzeyi yüksek ilköğretim öğretmenlerinin öğrencilere yaklaşım biçimlerinin incelenmesi. Eğitim ve Bilim, 33 (147), 106-120.

Karasar, N. (2012). Bilimsel araştırma yöntemi. Ankara: Nobel Yayın Dağıtım.

Karataş, S. ve Güleş, H. (2010). İlköğretim Okulu Öğretmenlerinin İş Tatmini İle Örgütsel Bağl11ı̆̆1 Arasındaki İlişki. Uşak Üniversitesi Sosyal Bilimler Dergisi, 3 (2), 74-89.

Kaya, O. Ş. (2010). Ankara ilinde çalışan polislerin tükenmişlik düzeylerinin bazı değişkenler açısından incelenmesi. Yayımlanmamış Yüksek Lisans Tezi. Çukurova Üniversitesi Sosyal Bilimler Enstitüsü Eğitim Bilimleri Anabilim Dalı: Adana.

Kaya, F. (2014). Duygusal emek ile tükenmişlik ve iş doyumu arasındaki ilişkinin incelenmesi: Aile ve Sosyal Politikalar Bakanlı̆̆ına bağlı huzurevlerinde çalışan yaşlı bakım personeline yönelik bir araştırma. Yayımlanmamış Yüksek Lisans Tezi. Celal Bayar Üniversitesi Sosyal Bilimler Enstitüsü İşletme Ana Bilim Dalı Yönetim ve Organizasyon Programı: Manisa.

Kayabaşı, Y. (2008). Bazı değişkenler açısından öğretmenlerin mesleki tükenmişlik düzeyleri. Sosyal Bilimler Dergisi, 20, 191-212.

Kıral, B. (2008). Ortaöğretim okul yöneticilerinin yaşadıkları stres belirtileri düzeyi. yayımlanmamış yüksek lisans tezi. Kırıkkale Üniversitesi Sosyal Bilimler Enstitüsü: Kırıkkale. 
Koruklu, N., Feyzioğlu, B., Özenoğlu-Kiremit, H. ve Aladağ, E. (2013). Öğretmenlerin iş doyumu düzeylerinin bazı değiş̧kenlere göre incelenmesi. Mehmet Akif Ersoy Üniversitesi Eğitim Fakültesi Dergisi, 13 (25), 119-137.

Maslach, C. (1976). Burned-out. Human Behavior, 9 (5), 16-22.

Maslach, C. ve Jackson, S. E. (1981). The measurement of experienced burnout. Journal of Occupational Behaviour, 2, 99-113.

Maslach, C. ve Jackson, S. E. (1985). The role of sex and family variables in burnout. Plenum Publishing Corporation. 12 (7/8), 837-851.

Nagar, K. (2012). Organizational commitment and job satisfaction among teachers during times of burnout. VIKALPA. 37 (2), 43-60.

Norfolk, D. (1989). İş hayatında stress. İstanbul: Form yayınları.

Okray-Kocabıyık, Z. ve Çakıcı, E. (2008). Sağlık çalışanlarında tükenmişlik ve iş doyumu. Anatolian Journal of Psychiatry. 9, 132-138.

Oruç, S. (2007). Özel eğitim alanında çalışan öğretmenlerin tükenmişlik düzeylerinin bazı değişkenler açısından incelenmesi (Adana İli Örneği). Yayımlanmamış Yüksek Lisans Tezi. Çukurova Üniversitesi Sosyal Bilimler Enstitüsü İlköğretim Ana Bilim Dalı: Adana.

Otacıoğlu, S. G. (2008). Müzik öğretmenlerinde tükenmişlik sendromu ve etkileyen faktörler. İnönü Üniversitesi Eğitim Fakültesi Dergisi, 9 (15), 103-116.

Ören, N. ve Türkoğlu, H. (2006). Öğretmen adaylarında tükenmişlik. Muğla Üniversitesi Sosyal Bilimler Enstitüsü Dergisi, 16.

Özben, Ş. ve Argun, Y. (2003). İlköğretim öğretmenlerinin umutsuzluk ve tükenmişlik düzeyleri üzerine bir araştırma. Ege Eğitim Dergisi, 3(1), 36-48.

Özcan, T. (2008). Pendik bölgesinde görev yapan öğretmenlerin tükenmişlik düzeylerinin bazı demografik değişkenler açısından incelenmesi. Yayımlanmamış Yüksek Lisans Tezi. Yeditepe Üniversitesi Sosyal Bilimler Enstitüsü Eğitim Yönetimi ve Denetimi Bölümü Tezli Yüksek Lisans Programı: İstanbul.

Polat, G., Topuzoğlu, A., Gürbüz, K., Hotalak, Ö., Kavak, H., vd. (2009). Bilecik ili, Bozüyük ilçesi, lise öğretmenlerinde tükenmişlik sendromu. TAF Preventive Medicine Belletin, 8 (3), 217-222.

Raj, T. ve Lalita. (2013). Job satisfaction among teachers of private and government school: a comparative analysis. International Journal of Social Science \& Interdisciplinary Research (IJSSIR). 2 (9), 151158.

Rowshan, A. (2003). Stres yönetimi, hayatinizin sorumluluğunu almak için stresi nasil yönetebilirsiniz? İstanbul: Sistem Yayıncılik. 
Sağlam, A. Ç. (2007). Eğitim örgütlerinde kuramdan uygulamaya güdüleme. Ankara: Nobel Yayın Dağıtım

Sat, S. (2011). Örgütsel ve bireysel özellikler açısından iş doyumu ve tükenmişlik düzeyi arasındaki ilişki: Alanya'da banka çalışanları üzerinde bir inceleme. Yayımlanmamış Yüksek Lisans Tezi. Çukurova Üniversitesi Sosyal Bilimler Enstitüsü İşletme Anabilim Dalı: Adana.

Sempane, M. E., Rieger, H. S., Roodt, G. (2002). Job satisfaction in relation to organisational culture. SA Journal of Industrial Psychology. 28 (2), 23-30.

Tabachnick, B. G., Fidell, L. S. (2007). Using multivariate statistics. Boston: Pearson/Allyn\&Bacon.

Taşdan, M. ve Tiryaki, E. (2008). Özel ve devlet ilköğretim okulu öğretmenlerinin iş doyumu düzeylerinin karşılaştırılması. Eğitim ve Bilim, 33 (147), 54-70.

Tavşancıl, E. (2006). Tutumların ölçülmesi ve spss ile veri analizi. Nobel Yayın Dağıtım: Ankara.

Teltik, H. (2009). Okul öncesi öğretmenlerinin mesleki yeterlilik algılarının iş doyumu ve tükenmişlik düzeyleriyle ilişkisinin belirlenmesi. Yayımlanmamış Yüksek Lisans Tezi. Marmara Üniversitesi Eğitim Bilimleri Enstitüsü İlköğretim Anabilim Dalı Okul Öncesi Öğretmenliği Bilim Dalı: İstanbul.

Toker, B. (2007). Demografik değişkenlerin iş tatminine etkileri: İzmir'deki beş ve dört yıldızlı otellere yönelik bir uygulama, Doğuş Üniversitesi Dergisi, 8 (1), 92-107.

Tor, S. S. (2011). Örgütlerde iş tatminini etkileyen demografik faktörler ve verimlilik: Karaman gida sektöründe bir uygulama. Yayımlanmamış Yüksek Lisans Tezi. Karamanoğlu Mehmet Bey Üniversitesi Sosyal Bilimler Enstitüsü İşletme Anabilim Dalı: Karaman.

Türkçapar, Ü. (2012). Beden eğitimi öğretmenlerinin farklı değişkenler açısından iş doyumu düzeylerinin incelenmesi. GEFAD, 32 (2), 331-346.

Türkoğlu, M. (2008). Genel liselerde örgütsel kültürün iş doyumuna etkisi (Malatya İli Örneği). Yayımlanmamış Yüksek Lisans Tezi. Fırat Üniversitesi Sosyal Bilimler Enstitüsü Eğitim Bilimleri Ana Bilim Dalı: Elazı̆g.

Ural A. ve Kılıç, İ. (2005). Bilimsel araştirma süreci ve SPSS ile veri analizi. Ankara: Detay Yayıncılık

Uyar, S. ve Erdinç, S. B. (2011). Muhasebe personelinin iş doyumu ve tükenmişlik düzeyi. MÖDAV, 1, 213232.

Üngüren, E., Doğan, H., Özmen, M. ve Tekin, Ö. A. (2010). Otel çalışanlarının tükenmişlik ve iş tatmini düzeyleri ilişkisi. Yaşar Üniversitesi Dergisi. 17 (5), 2922-2937.

Watts, G. J. (2013). Relationship among self-efficacy, social support, job satisfaction, and teacher-related burnout, graduate faculty dissertation. Northcentral University Behavioral and Health Sciences: Arizona. 
Weiss, D. J., Dawis, R. V., England, G. W. ve Lofquist, L. H. (1967). Manual for the minnesota satisfaction questionnaire, Minnesota Studies in Vocational Rehabilitation: xxii. Minnesota University: Washington.

Yalçın, S. (2013). İlköğretim okulu öğretmenlerinin mesleki tükenmişlik düzeyleri ile stres, psikolojik dayanıklılık ve akademik iyimserlik arasındaki ilişki. Yayımlanmamış Yüksek Lisans Tezi. Gazi Üniversitesi Eğitim Bilimleri Enstitüsü Eğitim Bilimleri Ana Bilim Dalı Eğitim Yönetimi ve Denetimi Bilim Dalı: Ankara.

Yavaş, T. (2007). Kırsal alanda ve kent merkezinde çalışan sinıf öğretmenlerinin iş doyumu. Yayımlanmamış Yüksek Lisans Tezi. Fırat Üniversitesi Sosyal Bilimler Enstitüsü Eğitim Bilimleri Anabilim Dalı: Elazı ̆̆.

Yelboğa, A. (2007). Bireysel demografik değişkenlerin iş doyumu ile ilişkisinin finans sektöründe incelenmesi. Çağ Üniversitesi Sosyal Bilimler Dergisi, 4 (2), 1-19.

Yıldız, E. (2012). Mesleki tükenmişlik ve rehber öğretmenler üzerine bir araştırma. Sakarya Üniversitesi Sosyal Bilimler Enstitüsü Dergisi, 33 (2), 37-61.

Yılmaz, A. ve Ceylan, Ç. B. (2011). İlköğretim okul yöneticilerinin liderlik davranış düzeyleri ile öğretmenlerin iş doyumu ilişkisi. Kuram ve Uygulamada Eğitim Yönetimi, 17 (2), 277-394.

Yılmaz, H. ve Karahan, A. (2009). Bireylerin kişisel özellikleri yönünden iş doyum düzeylerine göre tükenmişlikleri: Afyonkarahisar ilinde bir araştırma. Süleyman Demirel Üniversitesi İktisadi ve İdari Bilimler Fakültesi Dergisi, 14 (3), 197-214.

Y1lmaz, M. ve Kıral, E. (2014). The relationship between motivation and job satisfaction of secondary school teachers, International journal of psycho-educational sciences, 3 (3), 74 -90

Yılmaz-Toplu, N. (2012). Okul öncesi ve ilköğretim ögrretmenlerinin tükenmişlik düzeyleri. Yayımlanmamış Yüksek Lisans Tezi. Adnan Menderes Üniversitesi Sosyal Bilimler Enstitüsü Eğitim Bilimleri Anabilim Dalı EYTEPE: Aydın.

Y1lmaz, T. (2013). Beden eğitimi öğretmenlerinin tükenmişlik düzeyleri: Ordu ili uygulaması. Yayımlanmamış Yüksek Lisans Tezi. Gazi Üniversitesi Beden Eğitimi ve Spor Anabilim Dalı: Ankara.

Yoğun-Erçen, A. E. (2007). Öğretmenlerin mesleki tükenmişlik düzeyleri: Mersin ilinde karşılaştırmalı bir inceleme. Çukurova Üniversitesi Eğitim Fakültesi Dergisi, 3 (34), 1-8.

\section{Extended Abstract}

\section{Purpose}

Job life and working compose of important parts of human life. People spend most of their daily life at workplaces and by planning duties related to their work. They get stressed at different levels both in their work life and daily life. Fundamentally, it is natural for people to get stressed in their lives. But, some people experiences stress at higher levels while some experience it at lower levels (Kural, 2008). What is crucial in that is to manage stress before it causes harmful results. A lot of causes like differentiation of social roles, 
experiencing misunderstanding in interpersonal relationships, competition's being in the foreground in work life and people's effort to prove themselves upon this, expectation of perfectionism in the workplace and resource shortage can affect employees' emotional health and can cause them to get stressed. Such that unmanaged stress can cause serious problems both personal and organizational dimensions.

Rapid and radical change occurring in informatics, technologic and social areas, can expose people with undesired situations by affecting their daily and work lives. People exposing undesired situations can sometimes achieve stressful conditions while they can also feel defeated, loneliness and burnout. Researchers have made many definitions of burnout. Maslach (1976), defined burnout as separation of a job's original meaning and purpose of it and a person's not being interested in his or her client. Burnout, can be harmful both for a person and his or her organization excessively. It is related with the concepts of job satisfaction, stress, life satisfaction and life quality. This relationship can be seen in variable reactions and attitudes of people under their life conditions. It can be said that life satisfaction and burnout levels of people may be negatively affected in the organizations where stress factors are intensive and in the organizations which cannot achieve job satisfaction. Hence, burnout be prevented as it can cause serious damages both for organization and individual

Teachers' ability to do their work effectively is directly related to the ability of perception of their skills and their self-confidence. However, problems that teachers encounter and have to struggle and cause them not having job satisfaction and experience burnout because of job stress. Hence, when job dissatisfaction that individuals experience because of different causes not removed, the possibility to experience burnout depending on dissatisfaction occurs. Teachers' job satisfaction and job burnout are important not only for them, but also the schools they worked in. Because their job satisfaction and burnout levels can affect the quality of the service and productiveness of the school and dependently carrying out the purposes and educational settings in general. With burning out of a teacher who feels dissatisfaction of his/her job and expresses, the quality of his/her profession may decrease. For this reason, it is important to know teachers job satisfaction and job burnout levels and determination of the relationship between them, when it is considered to raise awareness of teachers and provide suggestions to decrease their burnout and raise job satisfaction. It is expected that, revealed results can guide decision makers and practitioners. Thus the aim of this study is to determine the effect of teachers' job satisfaction on their job burnout levels. To reach this aim questions below were tried to be answered:

(1) What are the teachers' job burnout and satisfaction levels?

(2) Do teachers' job burnout and satisfaction levels differ significantly regarding to some demographical variables?

(3) Is there a significant relationship between teachers' job burnout and satisfaction levels?

(4) Do teachers' level of job satisfaction predict their burnout?

\section{Methodology}

The study is designed with casual comparative and relational screening model (Balc1, 2009; Karasar, 2012). With this study, it is tried to determine job satisfaction and burnout levels of teachers working at public schools and the effect of their job satisfaction on their burnout by the scales applied to teachers and according to their views. Study group of the research is composed of 162 voluntary teachers working in 7 public secondary schools in Incirliova county of Aydin. For data collection Minnesota Job Satisfaction Scale and Maslach Burnout Inventory were used. In the analysis of data descriptive and probative statistical techniques were used. In data analysis, frequencies, percentage, mean, parametric and nonparametric 
difference tests, correlation and regression analysis techniques were used (Tabachnick and Fidell, 2007). Statistical analysis of the data was made in a model that would determine the effect of independent variables on the dependent one. Burnout and job satisfaction levels of teachers were analyzed by mean and standard deviation; Significant differentiation of teachers' burnout levels according to independent variables (job satisfaction, gender, age, branch, seniority etc.) was analyzed by parametric differentiation tests ( $\mathrm{t}$-test and ANOVA) and nonparametric differentiation tests (Kruskal Wallis and Mann-Whitney U) was used. In the case of differentiation by ANOVA, Sheffe test was used to determine between which groups the differentiation is based on. Pearson Product-Moment Correlation Coefficient was used to determine whether there is a significant relationship between teachers' job satisfaction and burnout levels. The effect of job satisfaction on burnout was tested by regression analysis. The significance of the statistics were tested twosidedly in the level of .05 .

Results

Teachers experience burnout most in emotional exhaustion sub dimension, then personal accomplishment and depersonalization lastly in order. Teachers' emotional exhaustion is "medium" level and depersonalization and personal accomplishment are in "low" level.It is determined that, female teachers' burnout levels in the dimension of personal accomplishment is significantly higher than males, burnout levels of teachers who are at the age of 30 and below, is significantly higher than teachers' who are at the age of 31-35 and 36-40 in the dimension of depersonalization; single teachers' burnout levels in the dimension of depersonalization is significantly higher than married teachers'; burnout levels of teachers who had chosen their jobs involuntarily is significantly higher than teachers' who had chosen their jobs voluntarily in the dimension of emotional exhaustion.

It is found that secondary school teachers experience satisfaction intrinsically most, then generally and extrinsically at last. Teachers' intrinsic, extrinsic and general job satisfaction levels are in "I am satisfied" level. On the other hand, extrinsic job satisfaction levels of teachers who work in lower socio-economic areas, is significantly higher than teachers' working in medium level socio-economic areas; extrinsic job satisfaction levels of the teachers who had chosen their job involuntarily is significantly higher than their general job satisfaction and also their general job satisfaction level is significantly higher than their intrinsic satisfaction.

Positive significant relationships were found between teachers' internal and external satisfaction in medium level and general satisfaction levels in higher level. Medium level negative significant relationship was found between teachers' internal satisfaction and emotional exhaustion and personal accomplishment and low level negative significant relationship was found between internal satisfaction and depersonalization. There is a positive significant relationship between teachers' external satisfaction and general job satisfaction. Negative significant relationship was found between external satisfaction of teachers and emotional exhaustion in medium level and external satisfaction of teachers and depersonalization and personal accomplishment in low level. Negative significant relationship was found between teachers' general job satisfaction and emotional exhaustion in medium level and teachers' general job satisfaction and depersonalization and personal accomplishment in low level. Positive significant relationships were found between teachers emotional exhaustion and depersonalization and personal accomplishment. Lastly, there is a medium level positive significant relationship between teachers' depersonalization and personal accomplishment.

It was found that teachers' emotional exhaustion is predicted significantly by internal and external job satisfaction. Both internal satisfaction and external satisfaction are significant predictors of emotional 
exhaustion. As teachers' internal and external satisfaction levels rise, their emotional exhaustion levels decrease considerably.Linear combination of internal and external job satisfaction significantly predicts depersonalization of teachers. However, while it was determined that internal satisfaction is a significant predictor of depersonalization, external satisfaction is not. It was also found that as teachers' internal satisfaction rise, their depersonalization levels decrease considerably.It was found that linear combination of internal and external sub-dimensions of job satisfaction significantly predicts teachers' personal accomplishment. However, while it was determined that internal satisfaction is a significant predictor of personal accomplishment, external satisfaction is not. It was found that as teachers' internal satisfaction arise, their personal accomplishment arise, too.

Conclusion

Significant relationships were found between teachers' burnout and job satisfaction. Job satisfaction is a significant predictor of burnout. A teacher who experience job burnout, cannot be happy in the work life and correspondingly it causes dissatisfaction with his/her job. Therefore, skills, abilities and risks of being a teacher should be introduced to the people who wants to be teacher and opportunities for better selection should be given to them. Starting with secondary school, students should be directed suitable professions according to their interests and abilities and necessary guidance studies should be made in this process. Hence, as satisfaction arise as a result of conscious and voluntary selection of a profession, burnout can decrease. Studies for rising teachers' satisfaction (employee rights, organizational culture) can be made. In the current study it was found that female teachers' burnout levels are higher than male ones in the subdimension of personal accomplishment. Gender roles should be questioned and trainings on gender equality should be given to the families in order to overcome negative effects of gender roles and problems because of these effects. School administrators in lower socio-economic areas, should appreciate teachers' positive behaviors and support and motivate them. Studies with Directorates of National Education should be done to eliminate the inequality of opportunities. 